LBL $-\mathbf{- 3 0 8 5 2}$

DE93 001572

\title{
Case Studies of Thermal Energy Storage (TES) Systems: Evaluation and Verification of System Performance
}

January 1992

FINAL REPORT

H. Akbari and O. Sezgen

Applied Science Division

Lawrence Berkeley Laboratory

University of California

Berkeley, CA 94720

This study was sponsored by the California Institute for Energy Efficiency (CIEE) (Award No. B-90-03B) through the U.S. Department of Energy under Contract No. DE-AC03-76SF00098. 


\section{Acknowledgement}

We thank Mr. Ken Gillespie and Mr. Peter Tumbull, boih from Pacific Gas and Electric Company (PG\&E), for providing us the monitored data used in the case studies. We thank M. A. Piette for sharing with us her valuable experience with one of the case study buildings and providing many helpful comments and suggestions. 


\title{
Case Studies of Thermal Energy Storage Systems: \\ Evaluation and Verification of System Performance
}

\begin{abstract}
We have developed two case studies to review and analyze energy performance of thermal energy storage (TES) systems in commercial buildings. Our case studies considered two partial ice storage systems in Northern Califomia. For each case, we compiled historical data on TES design, installation, and operation. This information was further enhanced by data obtained through interviews with the building owners and operators.
\end{abstract}

The performance and historical data of the TES systems and their components were grouped into issues related to design, installation, operation, and maintenance of the systems. Our analysis indicated that (1) almost all problems related to the operation of TES and non-TES systems could be traced back to the design of the system, and (2) the identified problems were not unique to the TES systems. There were as many original problems with 'conventional' HVAC systems and components as with TES systems. Judging from the problems related to non-TES components identified in these two case studies, it is reasonable to conclude that conventional systems have as many problems as TES systems, but a failure in a TES system may have a more dramatic impact on thermal comfort and electricity charges.

The objective of the designers of the TES systerns in the case-study buildings was to design just-theright-size systems so that both the initial investment and operating costs would be minimized. Given such criteria, a system is typically designed only for normal and steady-state operating conditions-which often precludes due consideration to factors such as maintenance, growth in the needed capacity, ease of the operation, and modularity of the systems. Therefore, it is not surprising to find that these systems, at least initially, did not perform to the design intent and expectation and that they had to go through extended periods of trouble-shooting.

Neither of the two case-study TES systems had gone through a successful performance acceptance test and the systems had to go through a significant period of trouble-shooting and modifications before they became fully operational (i.e. shifting power form on-peak to off-peak period). The industry could benefit substantially from the introduction of a standard protocol for performance testing of systems. A successful protocol needs to address problems and define "performance" as well as provide guidelines for completion of a successful performance test and to suggest remedies for overcoming possible problems. Problems such as cleanup of construction debris, vibration of the compressors, and control of the system can usually be identified during the performance test of the system.

An integral objective of this study was to analyze the measured energy performance of TES systems and compare TES performance with "conventional" cooling systems. We compared the measured energy performance of TES systems with three conventional systems: a single-chiller system; a split system with two equal size smaller chillers; and a split system with two unequal units, one twice the capacity of the other. 
The measured performance of the case-study TES systems has not been disappointing. In the first case, after an initial period o1 trouble shooting and significant changes in operational strategies, the TES performed close to its design intent. Some of the design guidelines had been modified to address operational issues such as ease of control and maintenance of the system. In the second case, the system had been in fact under-sized and its capacity had not been sufficient to respond to growing cooling loads of the building.

In a typical summer week, for Case 1, the TES system saved 640,780 , and 660 on-peak kW compared to the single chiller, split chiller, and two-chiller systems, respectively, at a cost of additional energy use of 20.5, 37.6, 47.2 MWh per week. For Case 2, the diumal energy performance of the conventional single chiller system and the TES system were comparable; however, the TES system used less power than the conventional system. Once the performance of the TES with split and two chiller conventional systems were compared, the energy penalties increased substantially and the peak power savings diminished. 


\section{Table of Contents}

Chapter 1 Overview of the Case Studies and Analysis .............................................. 1

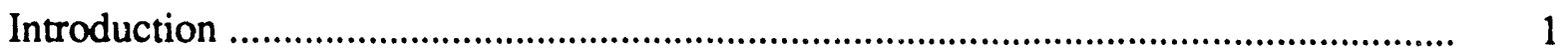

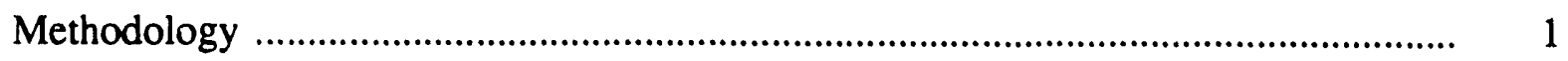

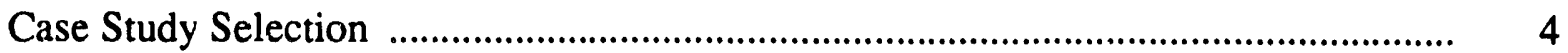

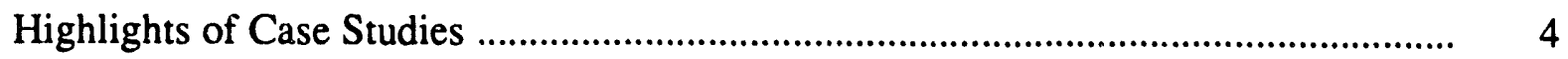

Chapter 2 Case 1: A Company Administrative Complex in San Ramon, California .......... 7

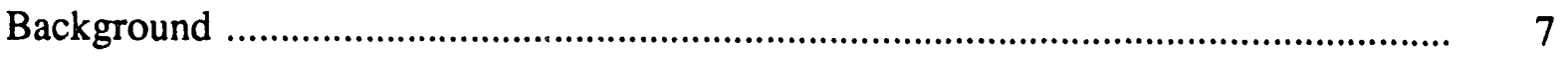

Building System Design and Description ........................................................... 7

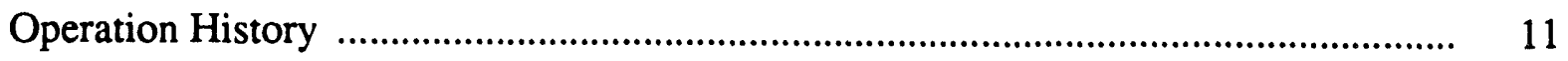

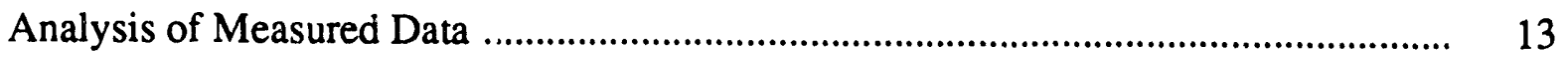

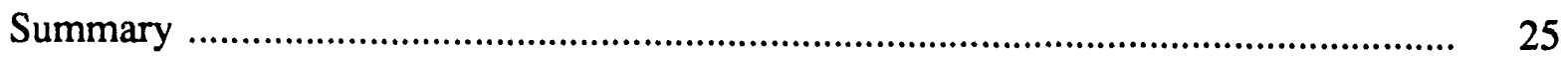

Chapter 3 Case 2: A 24-Story Office Building in San Francisco ........................................ 28

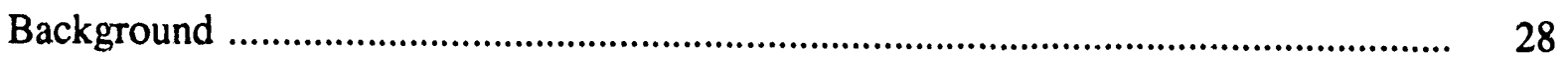

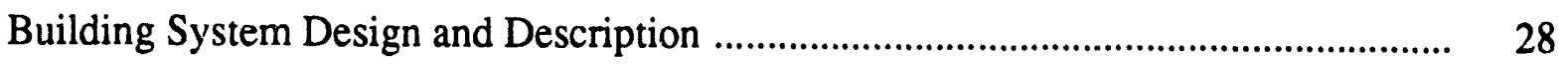

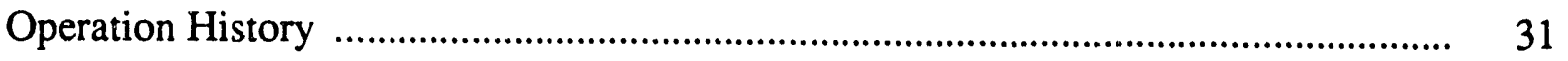

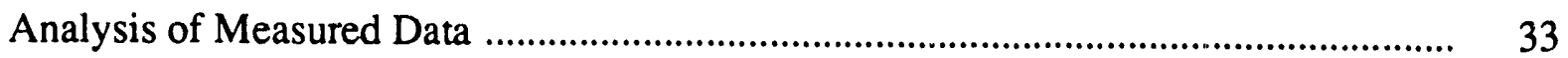

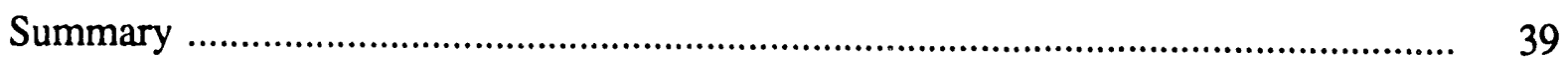

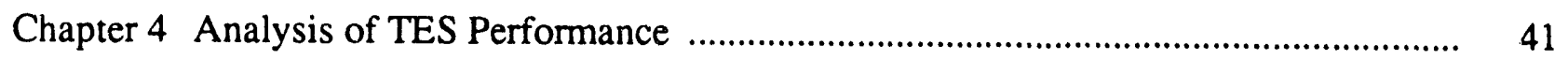

Design, Installation, Operational, and Maintenance Issues ..................................... 41

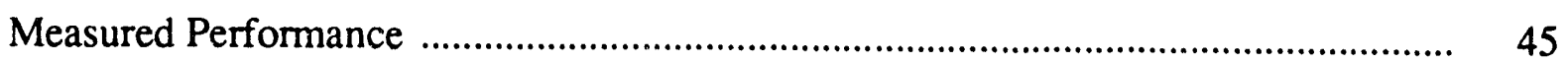

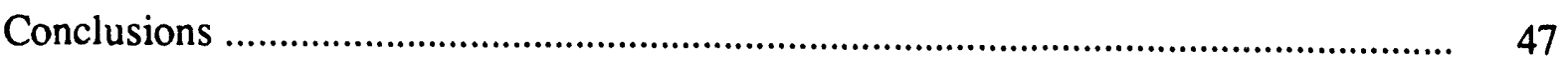

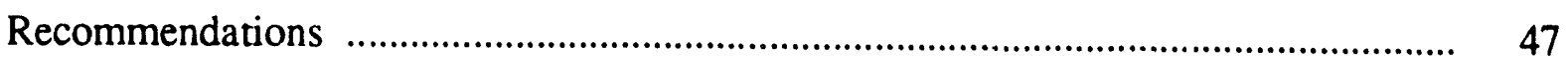

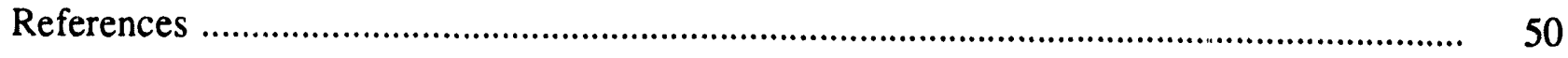




\section{Chapter 1: \\ Overview of the Case Studies and Analysis}

\section{Introduction}

Commercial buildings are major electricity users, and thus are of great interest to utilities in their resource-planning activities. Because the peak demand in commercial buildings generally contributes to the peak utility load, electric utilities concerned with their load shapes or capacity have instituted many programs aimed at load management. Thermal energy storage (TES) is a load management technology with great potential to shift load from peak to off-peak utility periods [1-4]. However, for many cases, the field performance data have indicated that this technology has substantial problems in real life applications, as might be expected with many new technologies [5-10].

To address some of the issues related to a successful implementation of TES systems, the California Institute for Energy Efficiency (CIEE) has contracted with San Diego State University (SDSU) and Lawrence Berkeley Laboratory (LBL) to study the performance of existing TES systems and to develop a diagnostic and acceptance procedure for future TES installations. The overall objectives of the project are to:

- Develop comprehensive diagnostic, acceptance, and start-up verification procedures for commercial TES systems, and

- Develop methods to quantify the impacts of TES technology on utilities and customer loads.

In this research project, LBL's responsibilities include developing two case studies for performance evaluations of the existing systems. The objective of the LBL study is to address the implementation issues related to TES by analyzing data from the two case studies where the day-to-day problems and performance of TESs can be monitored. This report only addresses the work performed at LBL. Efforts covering the other tasks of this project is covered in several reports from SDSU (ref quarterly reports to CIEE).

\section{Methodology}

In this project, we developed two TES case studies in Northern California for detailed analysis. For each case, we compiled historical information on TES design, installation, and operation. This information has been further enhanced through interviews with the building owners and operators. The performance and historical data are categorized in groups related to TES and to non-TES components; the TES group is further divided into subgroups related to design, installation, and operation of the system.

An integral objective of this project was to analyze the measured energy performance of the TES systems and compare TES performance with "conventional" cooling systems. The selection of a base conventional cooling system was of primary importance for this comparison. For most commercial buildings, conventional heating, ventilation, and air conditioning (HVAC) systems are designed for the peak buildingcooling demand (usually ASHRAE $97.5 \%$ design-day conditions), sometimes with an additional "safety factor." Consequently, most installed systems operate at part-load conditions throughout most of the year resulting in lower seasonal efficiency compared to the system performance at design-day conditions. More recently installed systems, however, consist of split chiller units so that during periods of low cooling demand only some of the chillers operate, leading to an improved part-load efficiency for the system. 
In our analysis, we compared the performance of TES systems with three simulated conventional systems. First, using the measured thermal load of the case study buildings and performance characteristics of the chillers, we calculated the energy performance of a single conventional system as a base for the comparison. ${ }^{1}$ Second, we simulated the cooling energy need for a conventional split system, assuming two smaller chillers with equal capacity. For the third conventional case, we assumed a split system with two unequal chiller units, one twice the capacity of the other. Additionally, where the measured data permitted, we tried to compare the measured energy performance of the installed conventional chillers with that of the TES system. This comparison was performed by identifying two weeks of similar building cooling demand (by comparing measured hourly, daily, and weekly cooling loads), one with TES operation and one with chiller operation only. Note that in this comparison, we did not have any information on either the outdoor weather conditions or whether the selected weeks were representative of the annual operation of either the conventional chillers or the TES system. ${ }^{2}$

For comparisons with conventional chiller systems, we developed a computer model, by which conventional chillers can be substituted for the TES system. Figure 1 shows an outline of the model. The input to the model include the measured building thermal load and the measured electricity consumption for the entire building, TES system, and other conventional chillers (if present). The model output consists of the weekly binned electricity use and peak demand for the measured data and the binned simulated electricity use and peak demand for the assumed conventional system. Binning is done for on-peak hours (Noon to $6 \mathrm{pm}$ Monday through Friday), part-peak hours (8:30 am to Noon and 6pm to 9:30 pm Monday through Friday) and off-peak hours (all other hours). Although for winter months, the electricity utility rates for on-peak and part-peak electricity use were the same, in our calculations we kept a separate account of electricity use during on-peak and part-peak periods.

The model is based on analysis of weekly data starting on Friday nights. The electricity used by the TES system is subtracted from the total building electricity consumption in order to estimate the building electricity use for all systems but TES. Then the electricity that would have been required to satisfy the building load using a conventional system is added to the remainder. This gives an estimate of the electricity consumption for the building with a hypothetical conventional system.

As we stated earlier, three conventional chilled water system configurations were considered in this model. A single large chiller that would meet the design-day cooling load of the building is the most obvious. On the other hand, it is a common practice in the industry to use a combination of smaller chillers to be able to use them closer to the full-load conditions and save energy. The sizing of these smaller chillers is a design-optimization problem and the solution depends heavily on the cooling-load profile of the particular building studied. For some load profiles, two chillers, where one has a capacity of $30 \%$ and the other a capacity of $70 \%$ of the design load, might give maximum savings in energy use; for other profiles, these number could change to $40 \%$ and $60 \%$.

1 This was an extension of work by Pietue [5] in which a conventional system was modeled based on hourly load data from actual TES.

2 In general, we expect that for similar building's cooling load the cooling energy requirement of the chillers to be about the same; the impact of the outdoor weather conditions on chiller performance is usually less than $20 \%$. 
Figure 1. A methodology to Compare TES Performance with Conventional Chillers

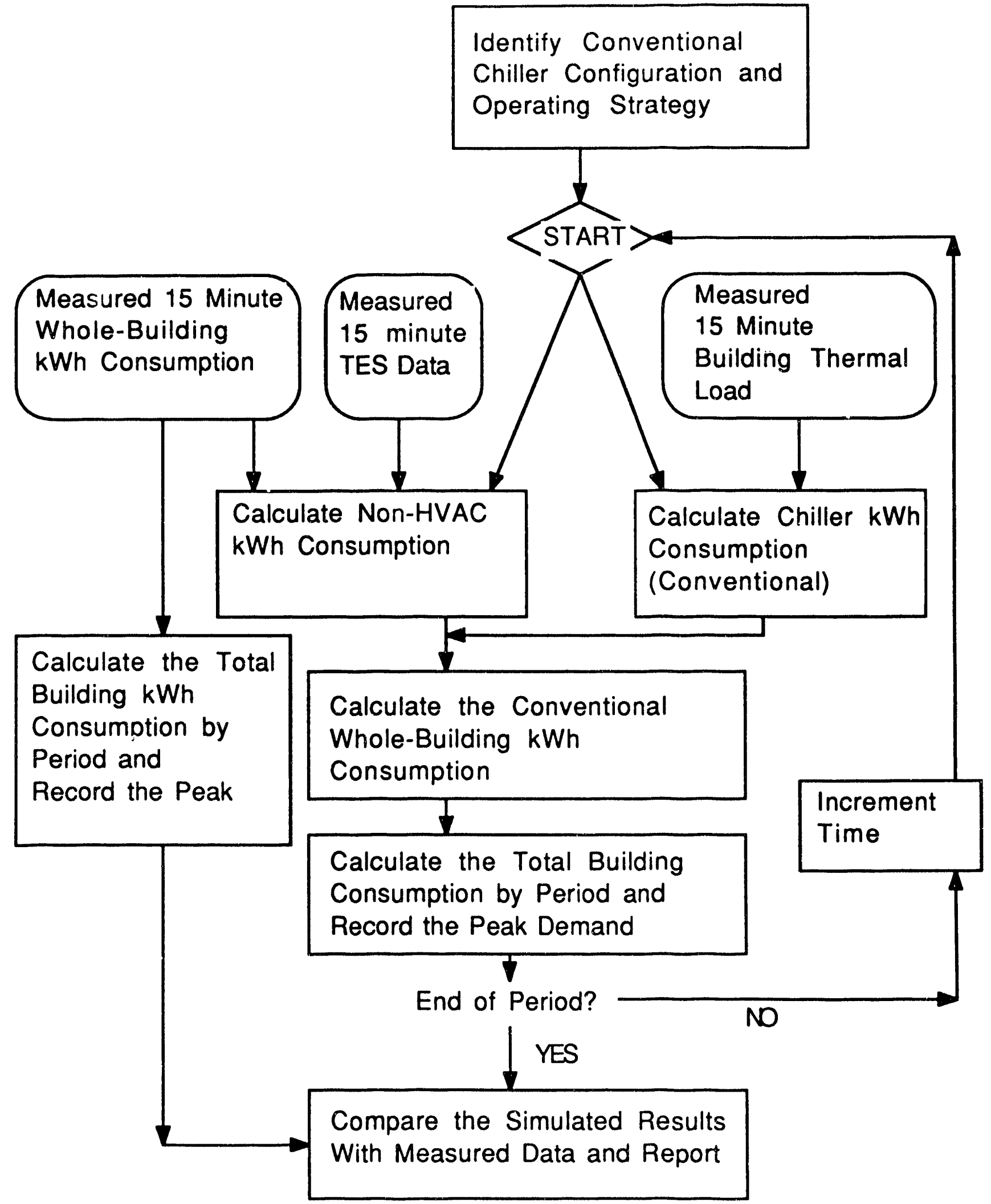


The model allows inputs of design options and operating strategies. The operating strategies employed for simulations were by no means optimal: they were just intuitive. For the split chiller system, we assumed an operating strategy where the smaller chiller operated when the cooling load was small, switching to the larger one as load increased and eventually operating both chillers in parallel.

\section{Case Study Selection}

The case studies presented in this report are intended to give insight to the researchers while they were working on the broader objectives of the project, namely: (1) developing comprehensive diagnostics, acceptance and start-up verification procedures for commercial TES systems and (2) developing methods to accurately quantify the impacts of TES technology on the utilities and customer loads.

We tried to select cases where both of the above objectives could be addressed. To address the first objective, we needed some record of the original design intent and a chronology of events during system installation, start-up period, and long-term operation. To address the second objective, we searched for cases where parameters pertinent to the study had been recorded for a significant length of time. Another consideration was the age of the facility. ${ }^{3}$

Pacific Gas and Electric Company (PG\&E) has been monitoring 12 TES installations for the last few years. We selected two cases out of these 12 and we obtained measured data that could be used to evaluate the performance of the systems. We also found out that for the selected two facilities the design engineers had published a description of their design work and goals (Gilbertson et al. (1984) and Goto et al. (1985)). The published information provided the basic characteristic data for the TES systems and the buildings. Other information regarding experience with system installation, start-up period, and longterm operation were obtained by interviewing the building owners and building engineers.

Although we intended to select cases that represented different environments (different building and system types in different climatic conditions), due to the limited number of available facilities for this study within the San Francisco Bay Area, both selected cases were office buildings with partial ice storage TES systems.

\section{Highlights of Case Studies}

Case 1 is a 4-story $\left(2,000,000 \mathrm{ft}^{2}\right)$ office building in San Ramon, CA, which is located approximately 15 miles east of San Francisco Bay and is separated from the bay by a range of hills. This separation makes the local climate more like the climate of the interior central valley of California. Case 2 is a 24-story highrise office building in San Francisco. Summaries of buildings and TES systems characteristics for these buildings are provided in Tables 1 and 2.

${ }^{3}$ During the past few years many new TES technologies have been developed and there are several new products in the market. It will be interesting to develop other case studies wilere the performance of new-generation TES systems can be analyzed. 
Table 1.

Case Study 1: Highlights of TES System Characteristics of an Office Building in East Bay

\begin{tabular}{|c|c|}
\hline $\begin{array}{l}\text { Floor area: } \\
\text { Design criterion for energy } \\
\text { consumption: } \\
\text { Simulated energy consump- } \\
\text { tion for the building at the } \\
\text { design phase: } \\
\text { Building peak cooling design } \\
\text { load: }\end{array}$ & $\begin{array}{l}2,000,000 \mathrm{ft}^{2} \text { in } 4 \text { stories } \\
30,000 \mathrm{Btu} / \mathrm{ft}^{2} \text { per year } \\
31,254 \mathrm{BTU} / \mathrm{ft}^{2} \text { year }\end{array}$ \\
\hline $\begin{array}{l}\text { Conventional system: } \\
\text { AHUs: }\end{array}$ & $\begin{array}{l}500 \text {-ton chiller for computer room, } 1000 \text {-ton add-on chiller for } \\
\text { day-time cooling } \\
\text { variable-air-volume systems with economizer cycle }\end{array}$ \\
\hline $\begin{array}{l}\text { compressors: } \\
\text { ice builders: } \\
\text { tank capacity: } \\
\text { condenser: } \\
\text { design goals for power shift: }\end{array}$ & $\begin{array}{l}\text { partial ice storage } \\
12,900 \text { ton-hours } \\
\text { (1) ice building during the night, without simultaneous melt } \\
\text { down; } \\
\text { (2) ice melting during the day, without compressor operation, } \\
\text { with a peak capacity of } 1,700 \text { tons; } \\
\text { (3) ice melting during the day, with simultaneous compressor } \\
\text { operation to generate chilled water, with a peak capacity of } \\
2,700 \text { tons. } \\
\text { three } 500 \text {-HP screw compressors; } 415 \text {-ton capacity in ice making } \\
\text { mode, } 647 \text {-ton capacity in chilled water generation mode } \\
24 \text { units of hot dipped galvanized, horizontal steel tubing. } \\
\text { three concrete tanks with a total capacity of } 1,080,000 \text { pounds of } \\
\text { ice } \\
\text { a } 9 \text {-acre artificial lake } \\
930 \mathrm{~kW} \text { reduction ( } 55 \% \text { of cooling demand) } \\
5,400 \mathrm{kWh} \text { daily on-peak energy use reduction } \\
1,550 \text { tons to off-peak period }\end{array}$ \\
\hline
\end{tabular}


Table 2.

Case Study 2: Highlights of TES System Characteristics of a High-Rise Office Building in San Francisco

\begin{tabular}{|c|c|}
\hline $\begin{array}{l}\text { Floor area: } \\
\text { Building peak cooling load: } \\
\text { AHUs: }\end{array}$ & $\begin{array}{l}265,000 \mathrm{ft}^{2}, 24 \text {-story } \\
460 \text { tons; daily peak } 3300 \text { ton-hours. } \\
\text { single-duct variable-air-volume (VAV) system with air handling } \\
\text { units on each floor. }\end{array}$ \\
\hline $\begin{array}{l}\text { TES System: } \\
\text { media: } \\
\text { storage capacity: } \\
\text { operative modes: } \\
\text { compressors: } \\
\text { ice builders: } \\
\text { tank capacity: } \\
\text { condenser: } \\
\text { design joals for power shift: }\end{array}$ & $\begin{array}{l}\text { partial ice storage } \\
1920 \text { ton-hours } \\
24 \text {-hour chiller operation: ice building during the night, direct } \\
\text { cooling and ice melting curing the day } \\
\text { two reciprocating, } 70 \text { tons compressors } \\
\text { factory-packaged ice builders consisted of } 1-1 / 4 \text { inch steel pipe } \\
\text { evaporator surface immersed in insulated open tanks } \\
\text { two } 960 \text { ton-hours } \\
\text { two in } 130 \text {-ton water-cooled condensers and cooling towers } \\
\text { TES was estimated to shift } 60 \% \text { of the on-peak electricity used } \\
\text { for cooling to part-peak or off-peak hours }\end{array}$ \\
\hline
\end{tabular}

The detailed analysis and discussion of these case studies are presented in a similar format in Chapters 2 and 3. Some background information is followed by a section in which the buiiding and the TES system, as they were originally designed, are described in detail. This section also provides information on how the designers intended the systems to be operated. Then, a chronology of events is presented as described by the building owners, building engineers, and other people who were interviewed. Then we discuss and examine the available measured data, addressing issues related to TES performance and comparing them with performances of conventional chilled water systems. Finally, in a summary section, performance, design, installation, operation, and maintenance procedures are commented on.

The synthesis and summary of case studies, conclusions on the analysis of the collected data, and comparison of the measured TES system performance with design intention and conventional HVAC systems are presented in Chapter 4 . Chapter 4 concludes the report by recommending a few research projects for further consideration. 


\section{Chapter 2}

Case 1: A Company Administrative Complex in San Ramon, Califomia

\section{Background}

This building is one of the 12 buildings that were monitored by PG\&E for TES system performance evaluation. The building has $2,000,000 \mathrm{ft}^{2}$ in four stories and is located approximately 15 miles east of the San Francisco Bay and is separated from the bay by a range of hills. This range makes the local climate more closely approach that of the interior central valley of California. The construction of the building was completed in 1986. The design engineers published an article in ASHRAE Journal in 1985 giving insight into the criveria they used during the design phase of the project and their expectations [12].

The building manager was contacted in early September and a meeting was arranged for September 27 , 1990. The building manager, the project manager in charge of following up the TES performance, and two other people from the mechanical services company in charge of system operation attended the meeting. Following the meeting a tour of the building was made.

\section{Building System Design and Description}

In the design phase, the owner's criterion for energy consumption was $30,000 \mathrm{Btu} / \mathrm{ft}^{2}$ (site) per year including HVAC, lighting and appliances (computer terminals, word processors, etc.). Ice storage was included into the design to shift both the electric demand $(\mathrm{kW})$ and the energy consumption (kWh) from the higher cost "on-peak" period to the lower cost "partial-peak" and "off-peak" periods. The system was designed to conform with the California Title 24 standards; and DOE-2 simulated energy consumption for the building was $31,254 \mathrm{BTU} / \mathrm{ft}^{2}$ (site) per year.

The estimated design-day total ouilding cooling luad of 2,750 tons was to be met with 4,125 GPM of chilled water varying in temperature down to $44^{\circ} \mathrm{F}$. The ice storage was sized to hold 12,900 ton-hours. The design was based on an operating schedule with the following three modes: mode (1) ice-building during the overnight period, without simultaneous meltdown; mode (2) ice-melting during the day, without compressor operation, with a peak capacity of 1,700 tons using 4,080 GPM of ice water ranging from 38 to $48^{\circ} \mathrm{F}$ through water-to-water heat exchangers; and mode (3) ice-melting during the day, with simultaneous compressor operation to generate chilled water, with a peak capacity of 2,700 tons with water-to-water heat exchangers plus the evaporator water shillers, using a combined flow-rate of 4,125 GPM of chilled water from 44 to $60^{\circ} \mathrm{F}$. The peak day cooling demand would be satisfied by employing mode (1) during off-peak hours and mode (3) during on-peak and partial-peak hours. This strategy would shifi 1,550 tons to off-peak electric rate periods. At $0.6 \mathrm{~kW} /$ ton, for what otherwise would have been chilled water generation, the gains corresponded to approximately $930 \mathrm{~kW}$ demand reduction and 5,400 $\mathrm{kWh}$ energy use reduction during the on-peak period.

Figures 2 through 4 show the plant and condenser side configuration. The central refrigeration plant (S1) is one of ice generation/storage/melting and chilled water generation on a daily basis. In addition, a separate 500-ton electrical centrifugal water chiller (S2) was designed to provide cooling for continuous computer room operation. This 500 -ton chiller was also intended to provide chilled water during the 
Figure 2. Case Study 1:

Refrigerant Loop of the Refrigeration Unit (S1)

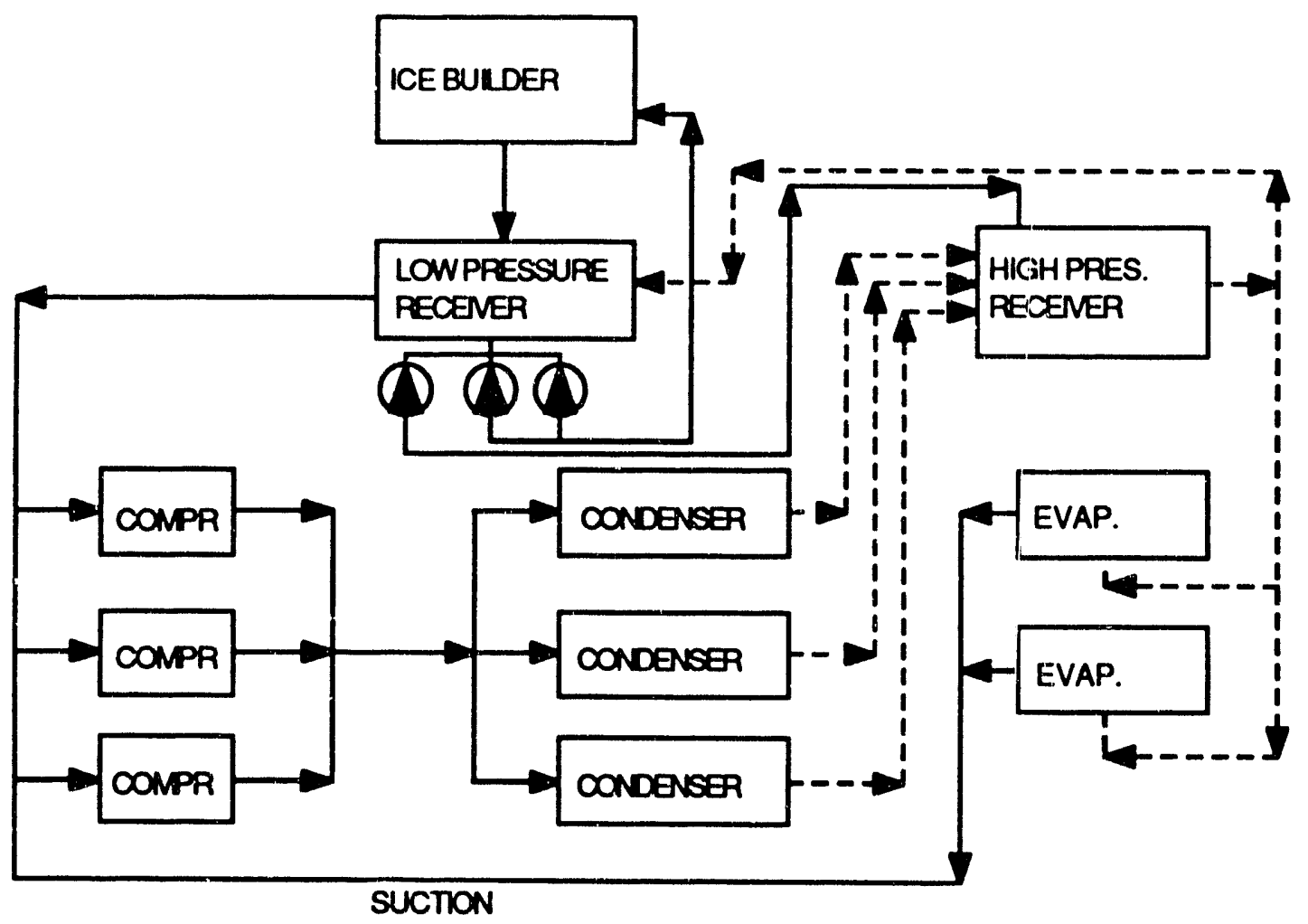


Figure 3. Case Study 1:

Chilled-Water Loop of the Central Plant

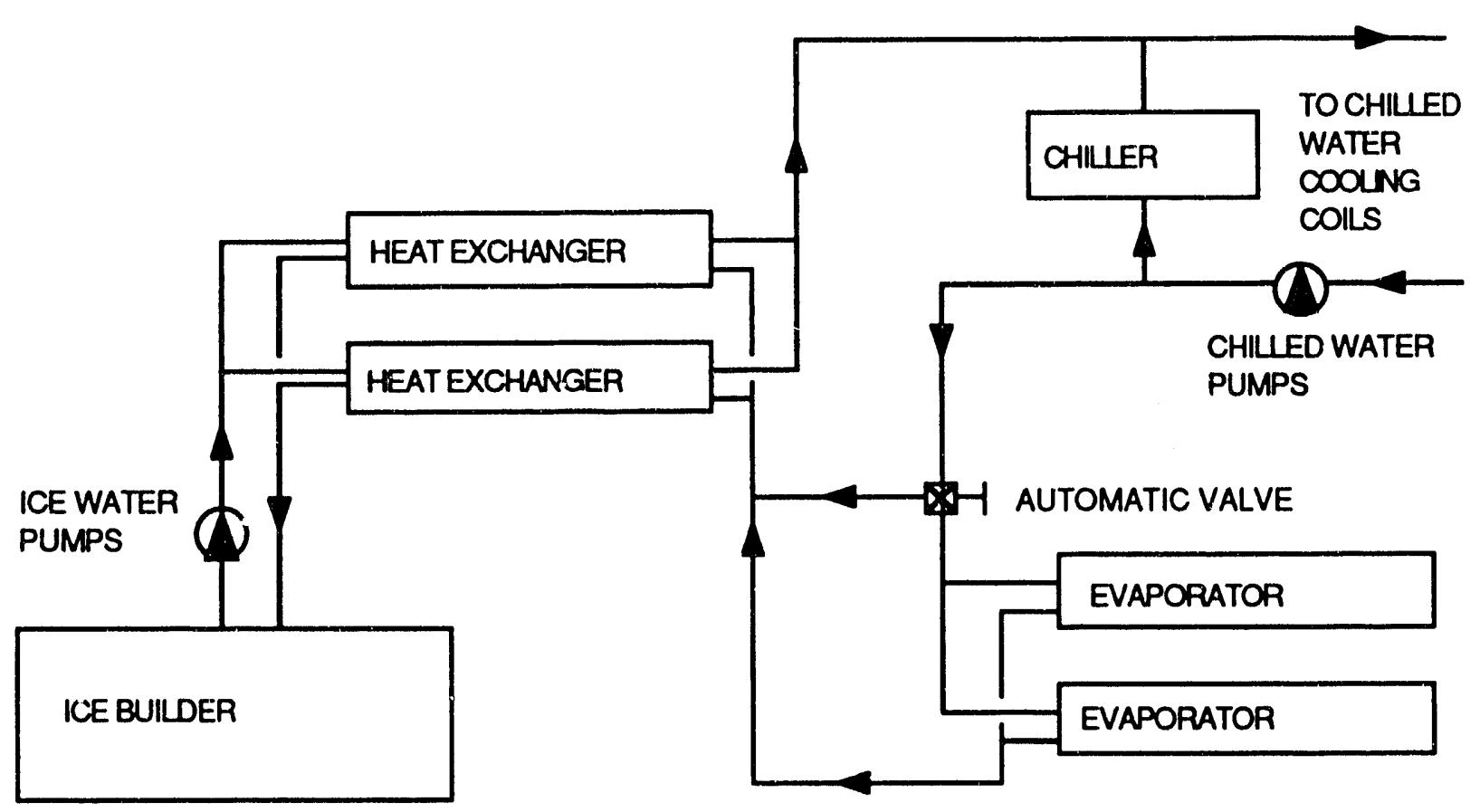


Figure 4. Case Study 1:

Condenser-Water Loop of the Central Plant

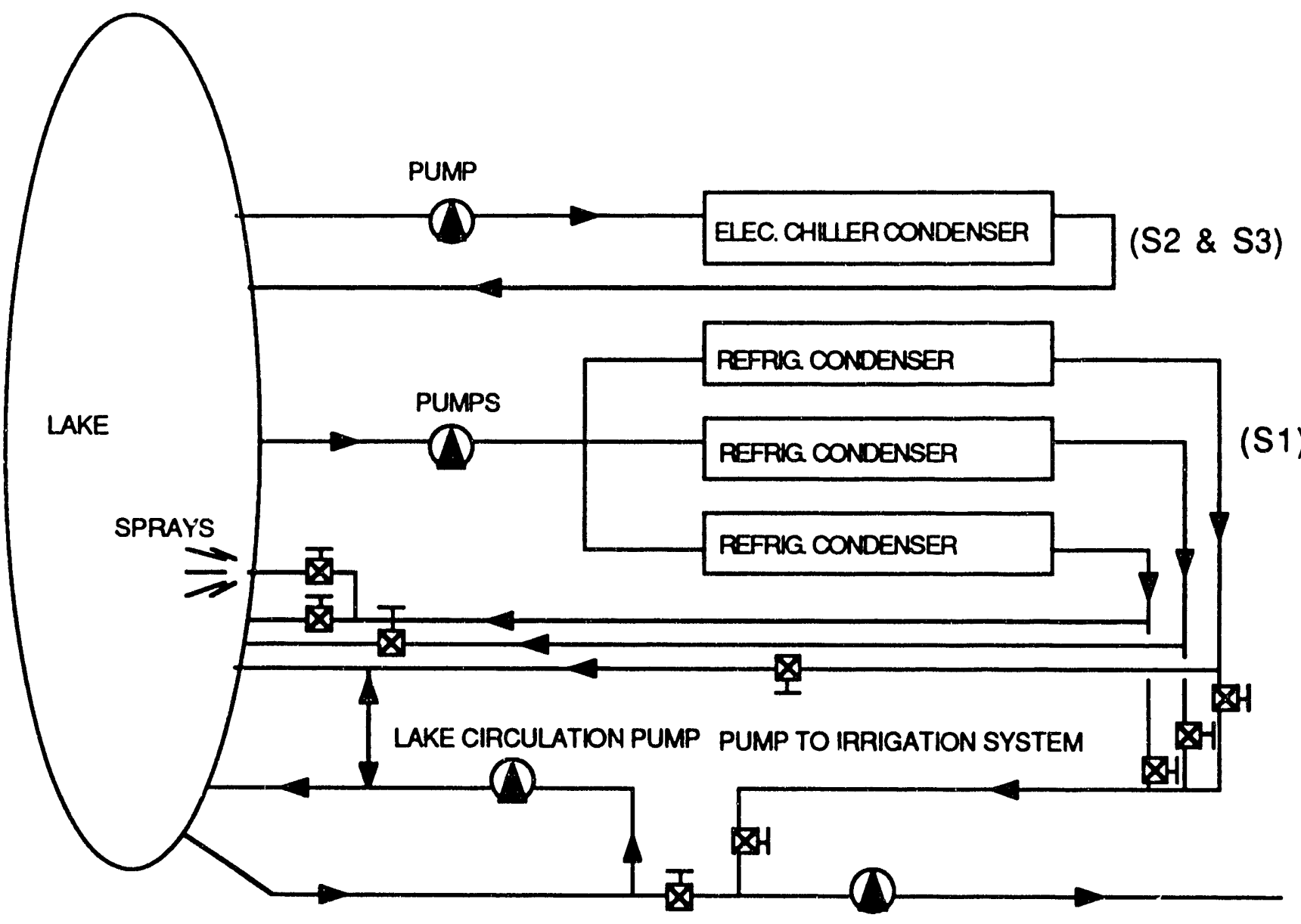


initial phases of building occupancy, prior to the completion of the ice plant. Certain sections of the building were utilized prior to the completion of the construction.

The refrigeration system (S1) (a liquid overfeed system) was designed to utilize three, $500 \mathrm{HP}$, screwtype compressors, operating on refrigerant R-22 and generate either ice or chilled water. When generating ice, at a $12^{\circ} \mathrm{F}$ suction temperature and a $90^{\circ} \mathrm{F}$ condensing temperature, the rated capacity of each compressor is 415 tons. When generating chilled water, at a $38^{\circ} \mathrm{F}$ suction temperature and a $95^{\circ} \mathrm{F}$ condensing temperature, the rated capacity of each compressor is 647 tons.

The ice builders consist of 24 units of hot dipped galvanized, horizontal steel tubing. Ice thickness of up to 2 inches is built up on the outside of the tubes. The ice builder units are configured in pairs-one on top of other. The storage system consists of three concrete tanks each having four pairs of ice builder units. The total combined storage capacity of the three tanks is $1,080,000$ pounds of ice. The amount of stored ice is measured with water level gages of the tanks.

Condensing water heat rejection from the refrigeration plant is to a nine-acre, 8-feet deep artificial lake. The main condensing water piping is designed to carry $6,900 \mathrm{GPM}$. The lake water is filtered to 0.0031 inch particles before retuming to the condenser. Primary heat rejection from the lake is by natural surface evaporation. The nighttime and daytime design lake water temperatures are $75^{\circ} \mathrm{F}$ and $80^{\circ} \mathrm{F}$, respectively. During peak loads and light wind conditions, sprays were designed to enhance the water evaporation rate and hence reduce the lake temperature. The spray system is comprised of 24 nozzles, each for 150 GPM. Two on-site wells provide for lake evaporation make-up. The well water is introduced into the condenser water supply to take advantage of the cooler well water for refrigerator condensing.

Air distribution for variable-air-volume systems is provided from distributed fan rooms, typically located in the basement to serve the floors above. The system includes a typical all-air-economizer cycle.

On the design day, the ice storage system was estimated to reduce cooling electricity demand during the on-peak hours by approximately 55\%, and shift more than half of the on-peak cooling energy needs to off-peak hours.

\section{Operation History}

The only system acceptance test for the TES system was a check to verify whether the system would build up 12,000 ton-hour ice within 12 hours, as it was designed to do. The test was not satisfactory and it was assumed that the system would be capable of meeting the design criteria and that the failure was due to the initial 'hot tank' conditions during the startup and testing period.

The refrigerant system was originally designed to run with R-22. However, compressors built to run with ammonia were shipped to the building by mistake. The seals on every one of the valves had to be changed to make the compressors run with R-22.

The following is a list of confronted problems and the modifications performed to remedy the problems during the operation phase of the project: 
1. Partly because of the short distance between the evaporator and the compressor, and partly because of the size limitation of the refrigerant accumulator, the gas reaching the compressor was saturated with liquid droplets, causing the compressors to vibrate severely when operating to chill water. (Note that this would have also been a problem for a conventional systems as well!) Because of this, they were never been able to operate the refrigeration system (S1) in the dual mode of nightime ice-making and daytime chilled water production. This plus the growth in the building peak cooling load from 2,700 to 3,500 tons (as it was measured) since 1986 led to installation of a new 1000-ton chiller (S3). The new chiller is a split system with two compressors and a single evaporator. Also, since there was no space in the mechanical room, the new chiller was placed in the garage. The current operating strategy is such that on hot days both chillers (S2 and S3) are operated and ice is melted to meet the cooling loads above the 1500 -ton level.

2. The operators encountered problems when they tried to perform maintenance on certain sections of the system without tuming the entire system off. Originally, there were not enough isolation valves-everything was welded. To remedy this problem, they added several isolation valves and cleanouts into the system.

3. Balancing the water level in the storage tanks posed an operational problem. To solve this problem, the tanks were connected with simple U-tubes and vacuum pumps (instead of installing regulating controls that would cost considerably more).

Having passed the initial start up, trouble-shooting, and fine-tuning of the system, the owner and operators are now generally satisfied with the performance of the system. But they still have three major concerns with the system:

1. A higher than predicated summertime lake temperature reduces the condenser capacity. Although the system was designed for a maximum condenser temperature of $80^{\circ} \mathrm{F}$, on hot days the lake water temperature exceeds $90^{\circ} \mathrm{F}$. (On extremely hot days, the discharge water from the condenser reaches $110^{\circ} \mathrm{F}$.) These high levels of condenser temperatures significantly reduce the chillers' performances to the extend that the system capacity is sometimes insufficient to meet the cooling load of the building.

2. In spite of their satisfaction with the performance of the system, building managers are very worried about the availability of spare parts and maintenance services. Contrary to suppliers of conventional chiller system equipment, some of the suppliers of their TES equipment are not in business anymore and, consequently, it takes months (rather than days) to acquire spare parts. This has created both financial worries and problems with maintaining the system.

3. The owner believes that most of the encountered problems are the result of having installed substandard equipment and of poor practice in installing the equipment. An example given was that at one point the ice coils cracked and the tanks were drawn down. In inspecting the system, it was found that $80 \%$ of the welds were defective. The owner also complained of poor product support and difficulties in maintaining the custom designed components such as the freon sniffers (sensors to detect freon leaks). 
The followings are highlights of some of the other problems the system is currently encountering:

4. When the ice in the tanks melts below 3,000 ton-hours, pieces of ice stan breaking up and throttling the pumps or blocking the pipes. Hence, for all practical purposes, the maximum operating capacity of the system is only 9,000 ton-hours $-75 \%$ of the intended design capacity of 12,000 ton-hours.

5. The well water has been affected by the drought; this has resulted in an increase in the concentration of the dissolved particles-mostly bicarbonates (currently at $750 \mathrm{ppm}$ )-leading to serious heat exchanger fouling. (Note that this would also been a problem for a conventional system.)

6. The refrigeration compressors (S1) are connected to the suction line one after another just after the line makes a 90 degree tum. The bend causes different suction pressures on the compressors and, consequently, the load on one of the compressors is much higher than the others. As a result, the oil bulkheads in this compressor break very frequently. Another associated problem is that oil migration occurs from the other two S1 compressors to the harder working compressor which has to be to transferred back every three days. (Note that this would also been a problem for a conventional system.)

7. Inventory of freon is checked once a week. There are difficulties in this procedure, which is statedependent $-24 \mathrm{psi}$ is required in the suction side. Operators must wait until ice builds and suction pressure goes up to 24 psi.

8. Ice makers and HVAC are controlled by products and software of different companies; some of these are incompatible, and this creates significant control problems.

\section{Analysis of Measured Data}

PG\&E provided the measured data for this building for the period of July 1989 to October 1990 . The data included 15-minute interval electricity consumption for the whole building, the refrigeration compressors (S1), refrigerator pumps, and individual chillers (S2 and S3); and thermal load for the building, the TES system (S1), and individual chillers (S2 and S3). The data also included measurements of the ice inventory in the tanks. We were warned that there were gaps in the data cspecially during the spring months of 1990 . The gaps in data were partly caused by maintenance activities and partly by difficulties encountered in downloading data from the resident control of the HVAC system. Given the state of the data, we were recommended by the PG\&E's technical staff in charge of the monitoring project to treat the data in a qualitative fashion rather than as a source of detailed performance statistics for the TES system.

The monitored data for a typical summer week are shown in Figure 5. The TES system measurements include: (a) total building electricity use, (b) electricity use for TES compressors (S1), (c) electricity use for TES pumps and controls, (d) total TES electricity use (b+c), (e) small chiller (S2) electricity use, (f) large chiller (S3) electricity use, (g) chilled-water pumps electricity use, (h) building cooling load, (i) TES cooling supply, (j) small chiller cooling supply, (k) large chiller cooling supply, (1) ice capacity, and (m) outside ambient temperature. This figure clearly shows the operating schedule of the TES compressors and the dynamics of the ice storage. The electricity used by the refrigerant pumps is included in the 
Figure 5. PG\&E's Monitored Data for the TES Syshem for the Period August 18-25, 1990

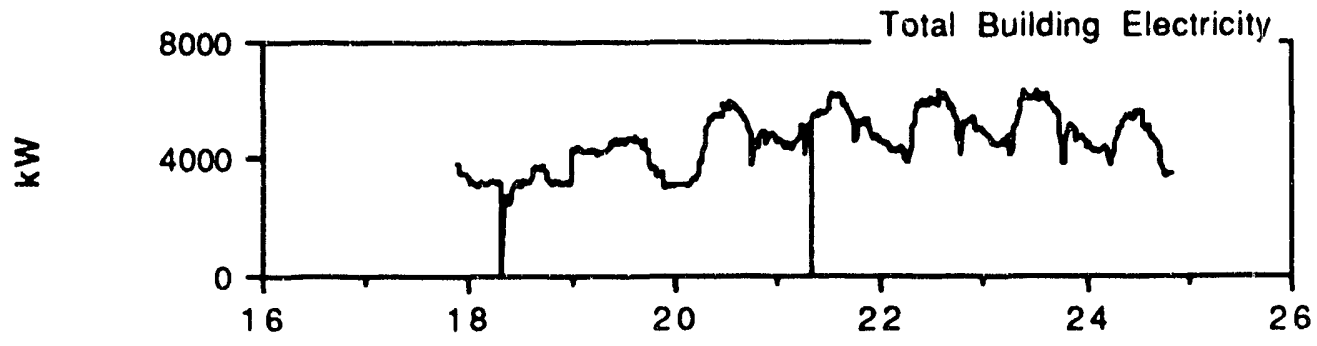

(a)

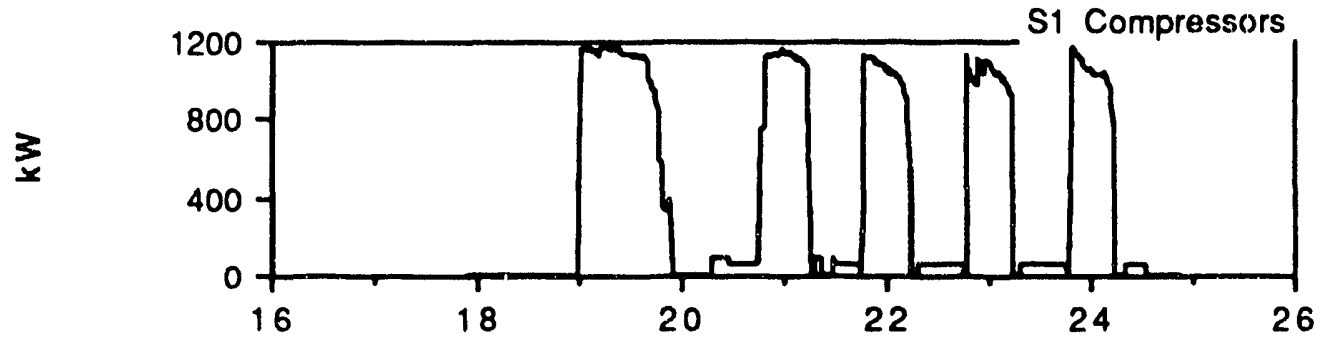

(b)

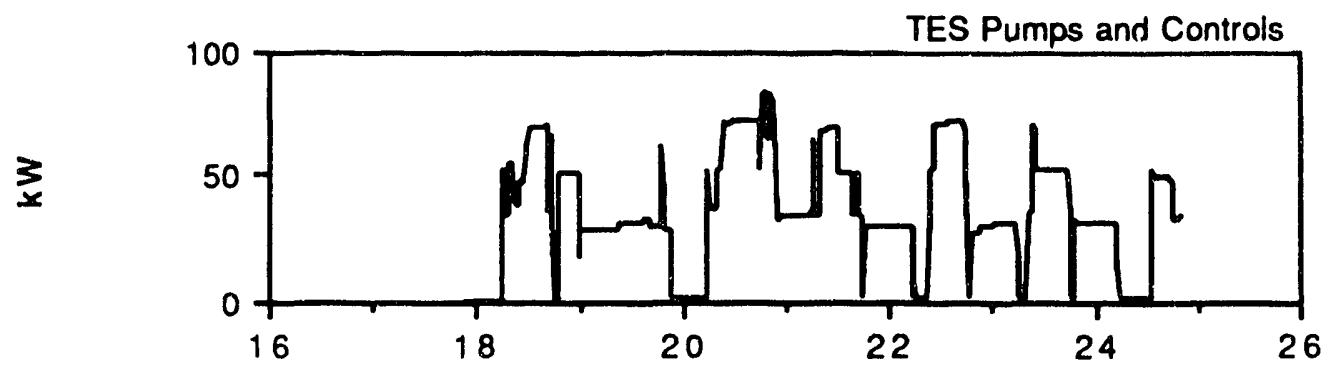

(c)

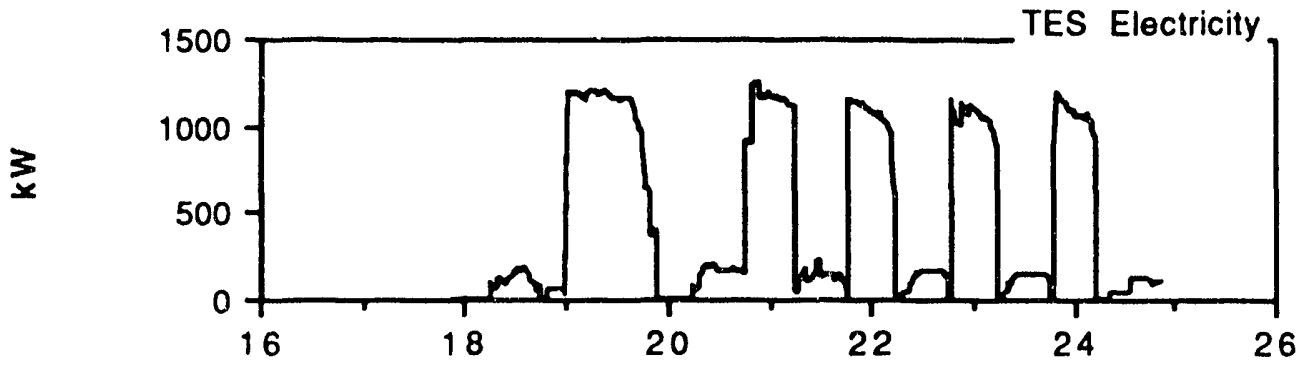

(d) 
Figure 5. PG\&E's Monitored Data for the TES System for the Period August 18-25, 1990 (continued)

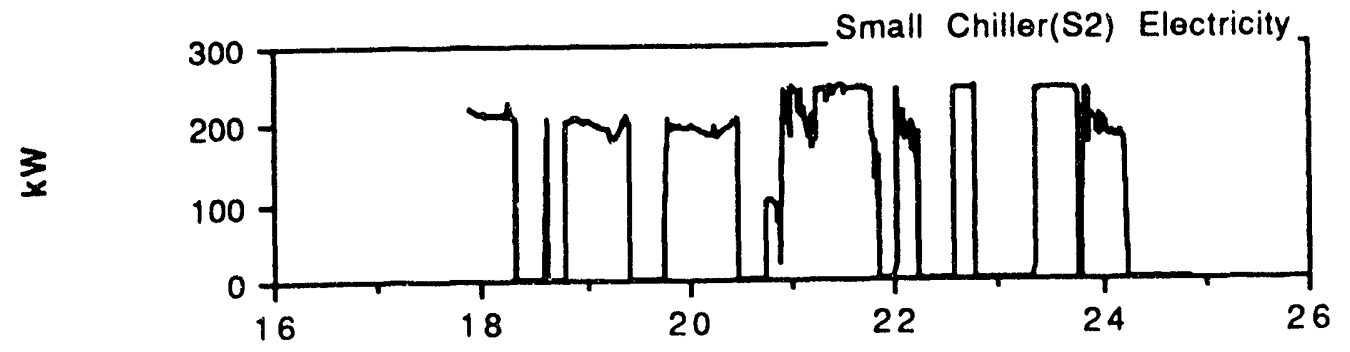

(e)

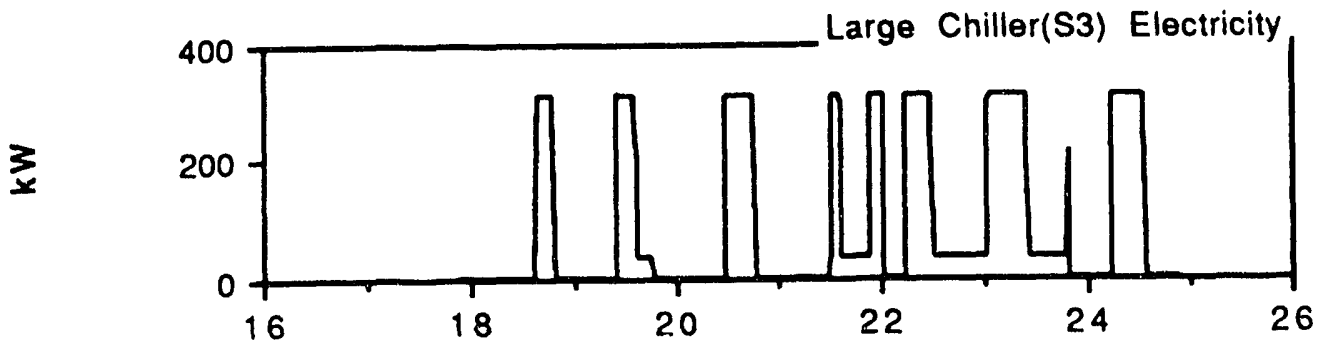

(f)

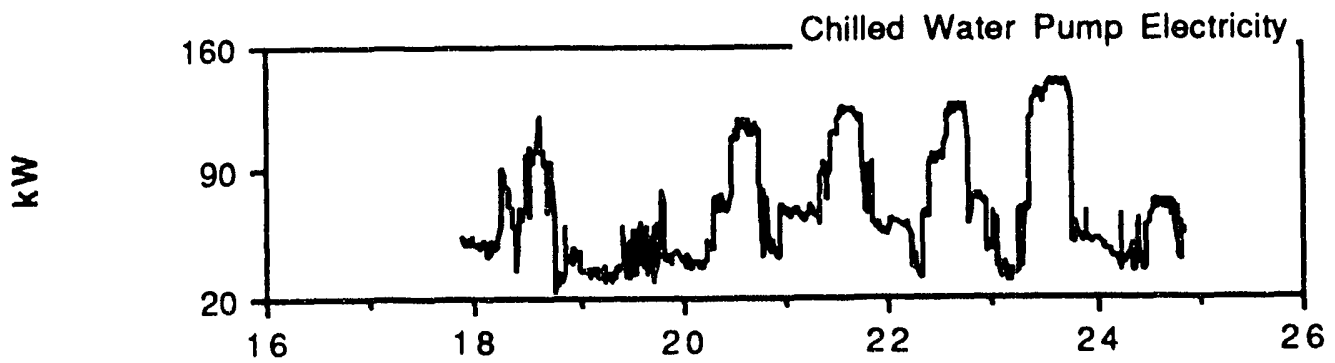

(g)

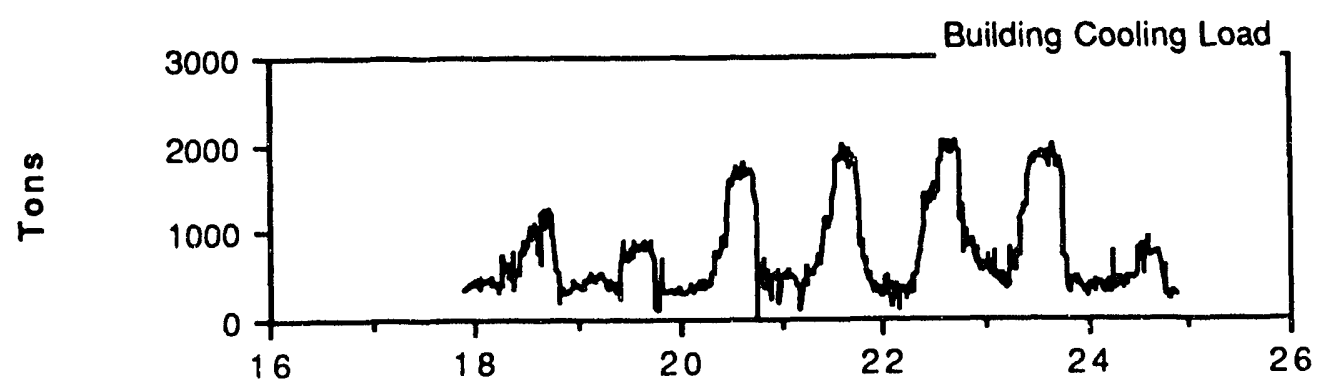

(h) 
Figure 5. PG\&E's Monitored Data for the TES System for the Period August 18-25, 1990 (continued)

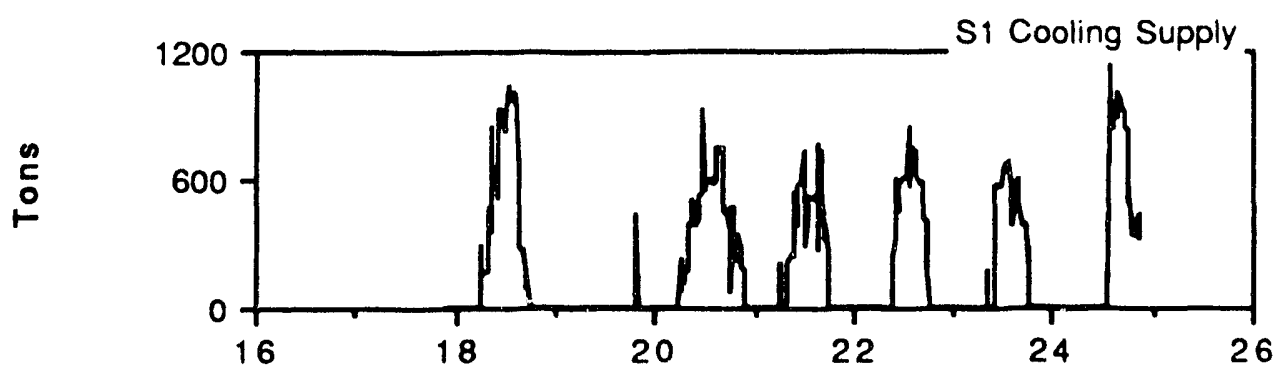

(i)

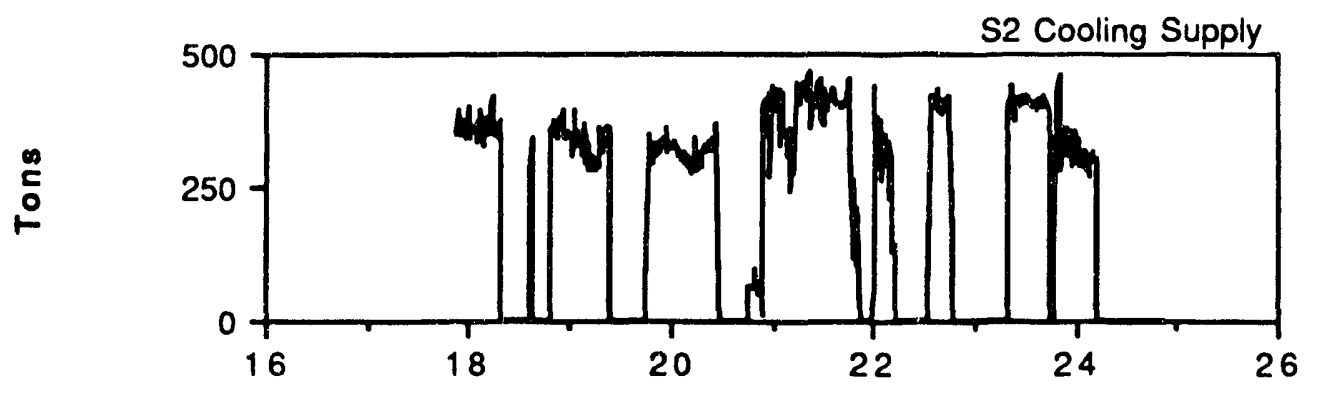

(j)

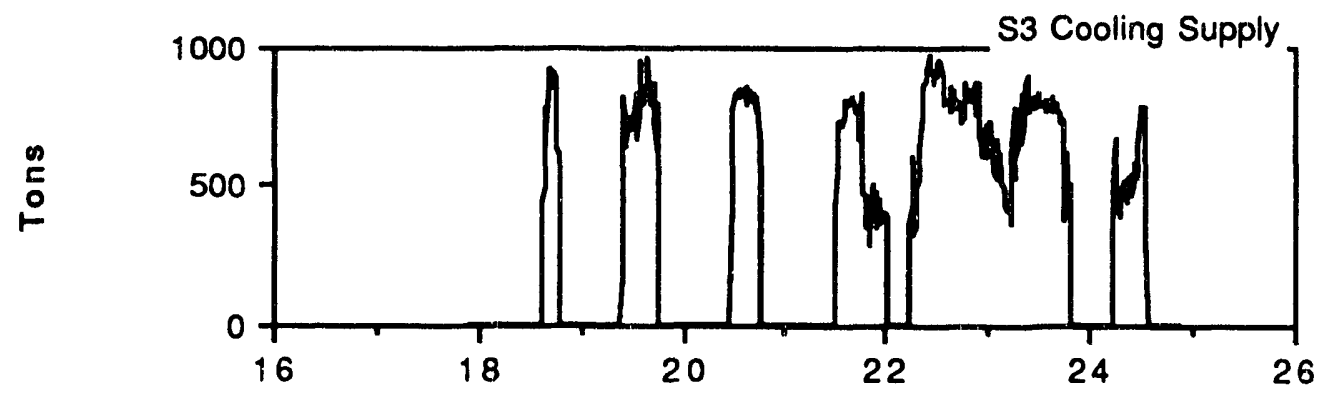

(k)

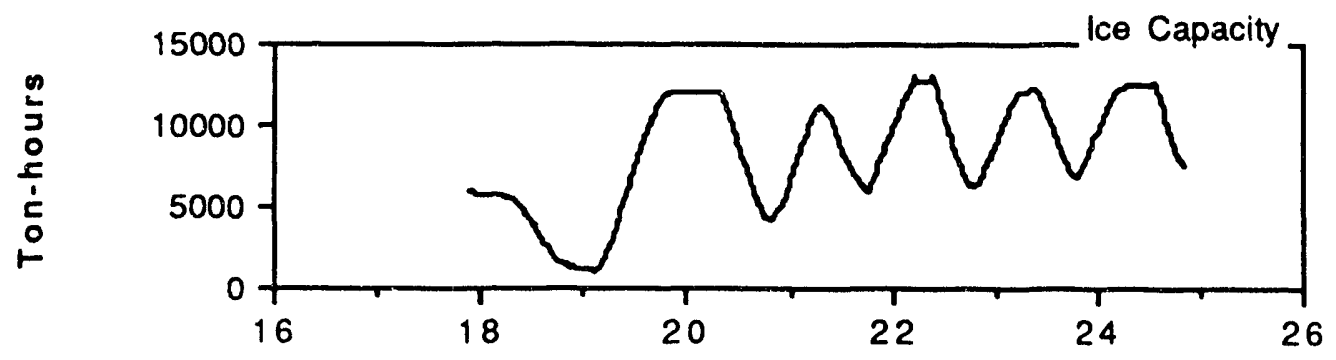

(1)

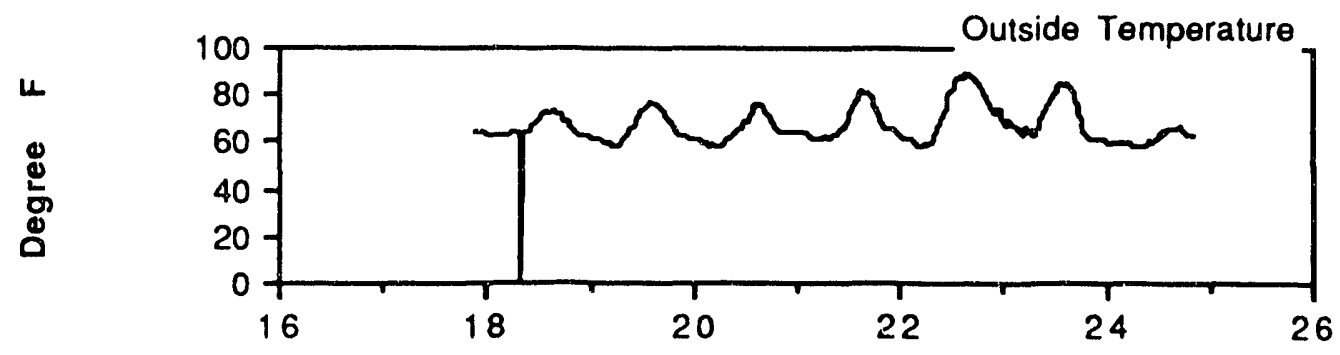

(m) 
TES electric load and the condenser pump electricity use is distributed to the TES and the chillers (S2 and S3) proportional to the load they met. The problems associated with the data were that: (1) the electricity measurements for the large chiller (S3) were not calibrated, and (2) the electricity consumption measurements for the chiller were intermittent during the summer months of 1990.

The data were used for three purposes: (1) determining the performance characteristics of the chill.... (?) comparing the instances where only chillers S2 and S3 were used to instances where the TES system was employed under similar load conditions (this would provide some indication of the advantages of employing the TES system), (3) simulating the performance of a conventional chilled water system for comparison with the existing TES system. We have estimated the performance characteristics of conventional chiller configurations to select the chiller configuration with the minimum electricity use to compare with the TES system. We then compared the measured TES system performance to the performance of the simulated conventional chilled water system for a warm week in summer, for an average week in summer, and for a warm week in winter.

A key factor for performing these comparisons was the actual coefficient of performance (COP) of the chillers (S2 and S3) and the refrigeration compressors (S1). We used the monitored data to estimate these COPs.

- For the TES system, as can be seen from Figure 5(d), the TES electricity use during the ice build-up period is fairly constant. We used data for this period to calculate a COP for the TES system. The estimated COP included the effects of compressors, refrigeration pumps, condenser pumps, and tanks heat losses. It should be noted that the effects of ice-water pumps are not included in the estimated COP.

- For estimating the COP of the small chiller (S2), the values for the chilled water electric loads shown in Figure 5(e) and the values for the thermal cooling supply shown in Figure 5(j) were used. As can be seen from these figures, during the times when the electricity consumption for S2 flattened at around the level of $210 \mathrm{~kW}$, the thermal cooling supply reached approximately 360 tons. This resulted in a steady-state COP of 6 including the condenser water pumps. It should also be noted that this value is for an average summer day and is probably a lower limit to the performance of the system in winter when the outdoor temperatures are more favorable for cooling purposes.

- Since we were warned that there were calibration problems with the electricity measurements for the large chiller (S3), based on the performance indicators from the other compressor (S2), we assumed a COP of 6 for the large chiller (S3) and recalibrated the data. ${ }^{4}$ Table 3 summarizes our findings.

Figures 6 through 9 depict the building loads for the months Decemier 1989, February, August, and September 1990. Figure 10 shows the chiller activity in February. The plateau at the level of approximately $150 \mathrm{~kW}$ represents the small (S2, 500 ton) chiller activity which was used to mainly cool the computer room. Early in February, chillers S2 and S3 were not used during the on-peak periods as the TES system was operational. During the last week of February, when the TES was not operational, the large chiller

4 The calculated summer- and winter time electricity use correction factors for the chiller (S3) were different. A correction factor of 1.66 was estimated for the week in August, while the estimated factor for the week in February was 1.99. 
Figure 6. Case Study 1: December 1989 Cooling Load

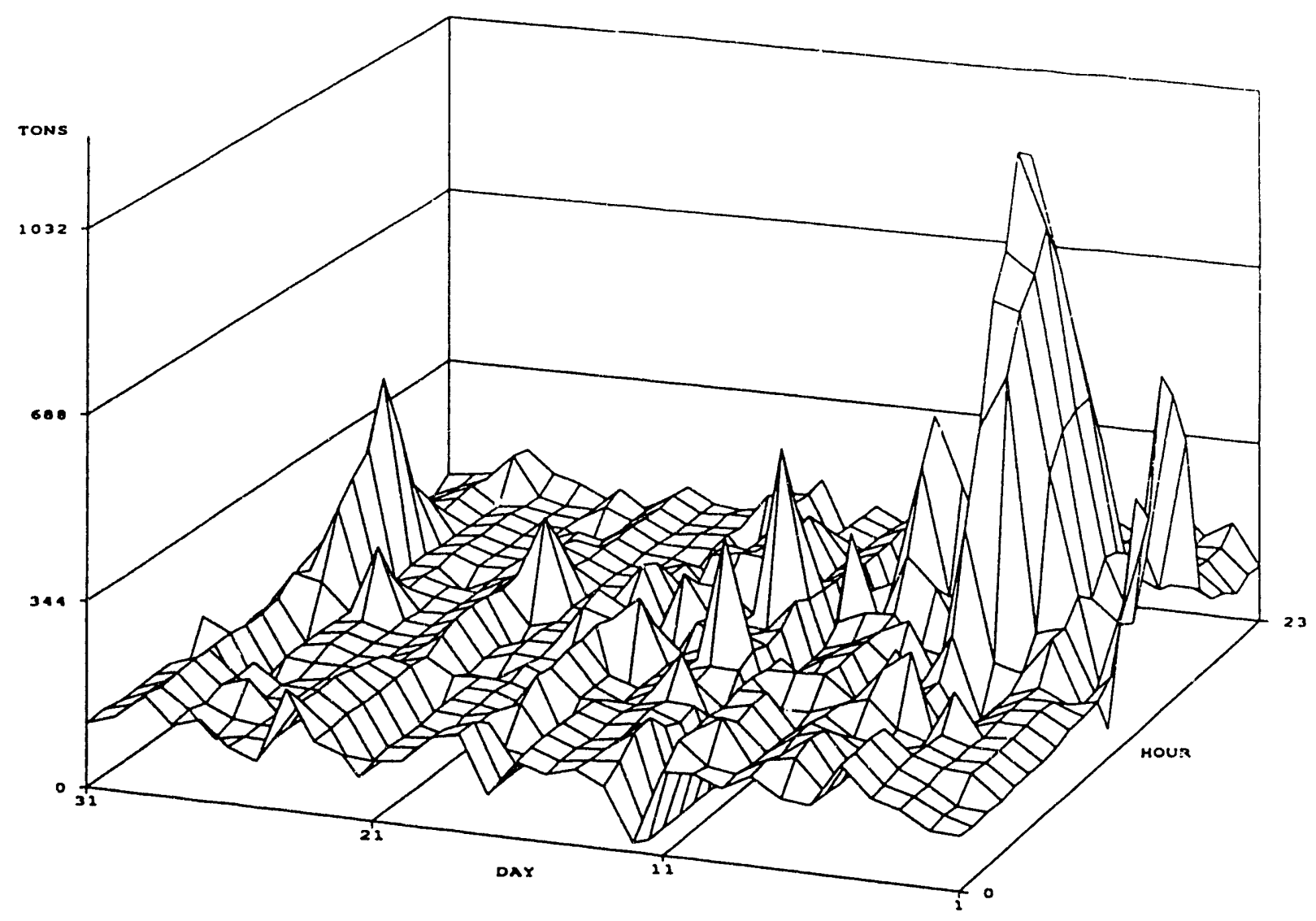

Figure 7. Case Study 1: February 1990 Cooling Load

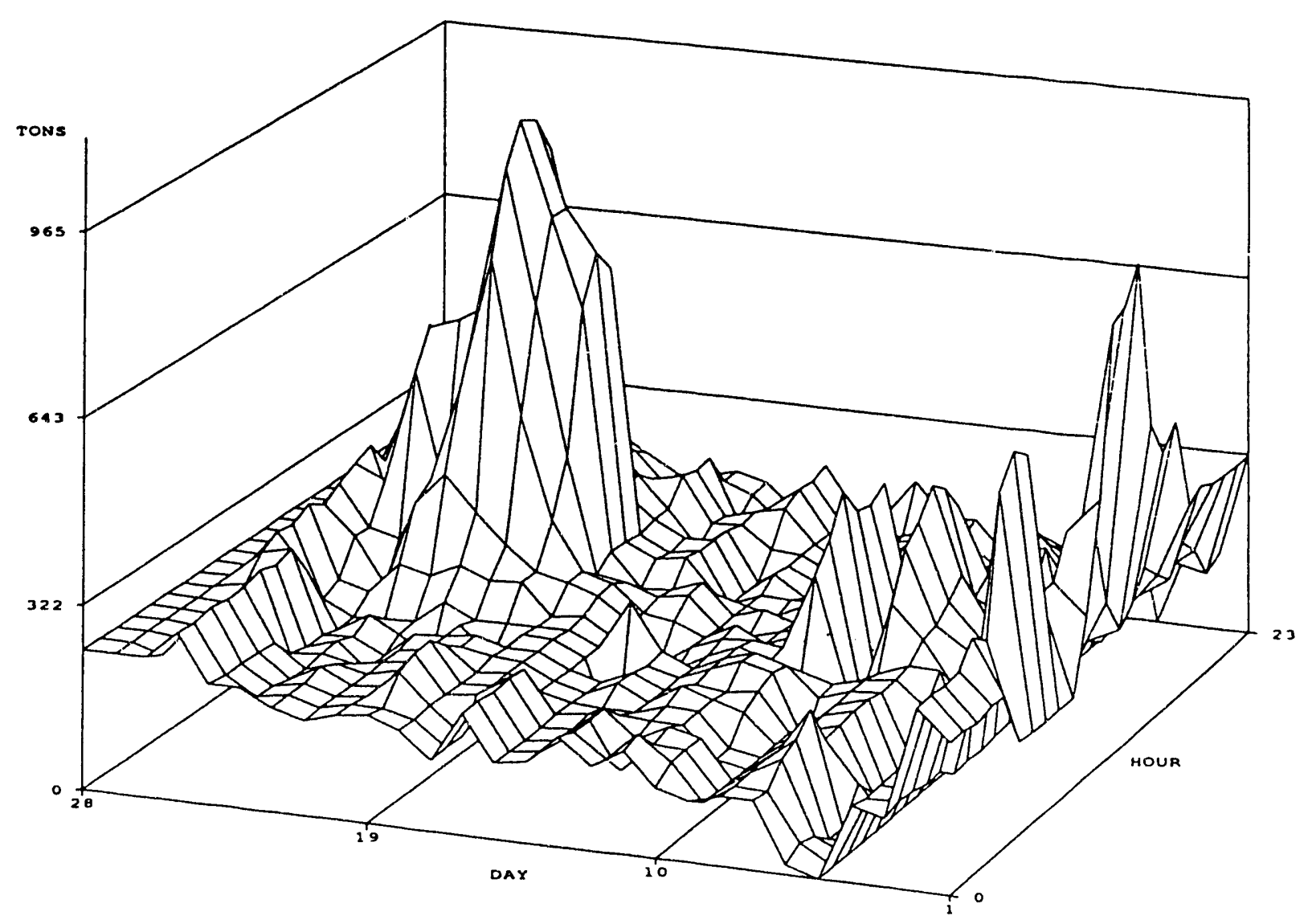

$-18-$ 
Figure 8. Case Study 1: August 1990 Cooling Load

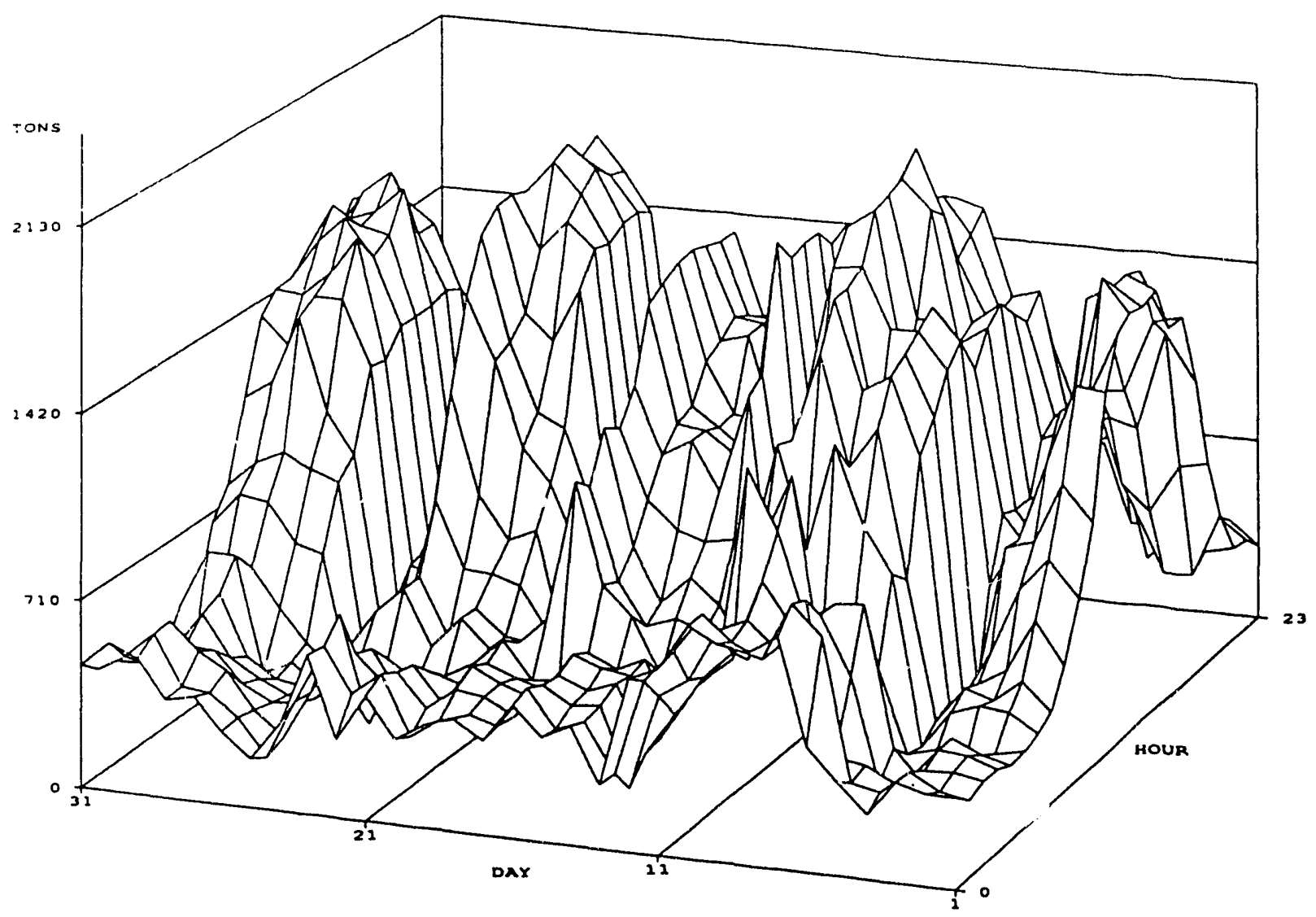

Figure 9. Case Study 1: September 1990 Cooling Load

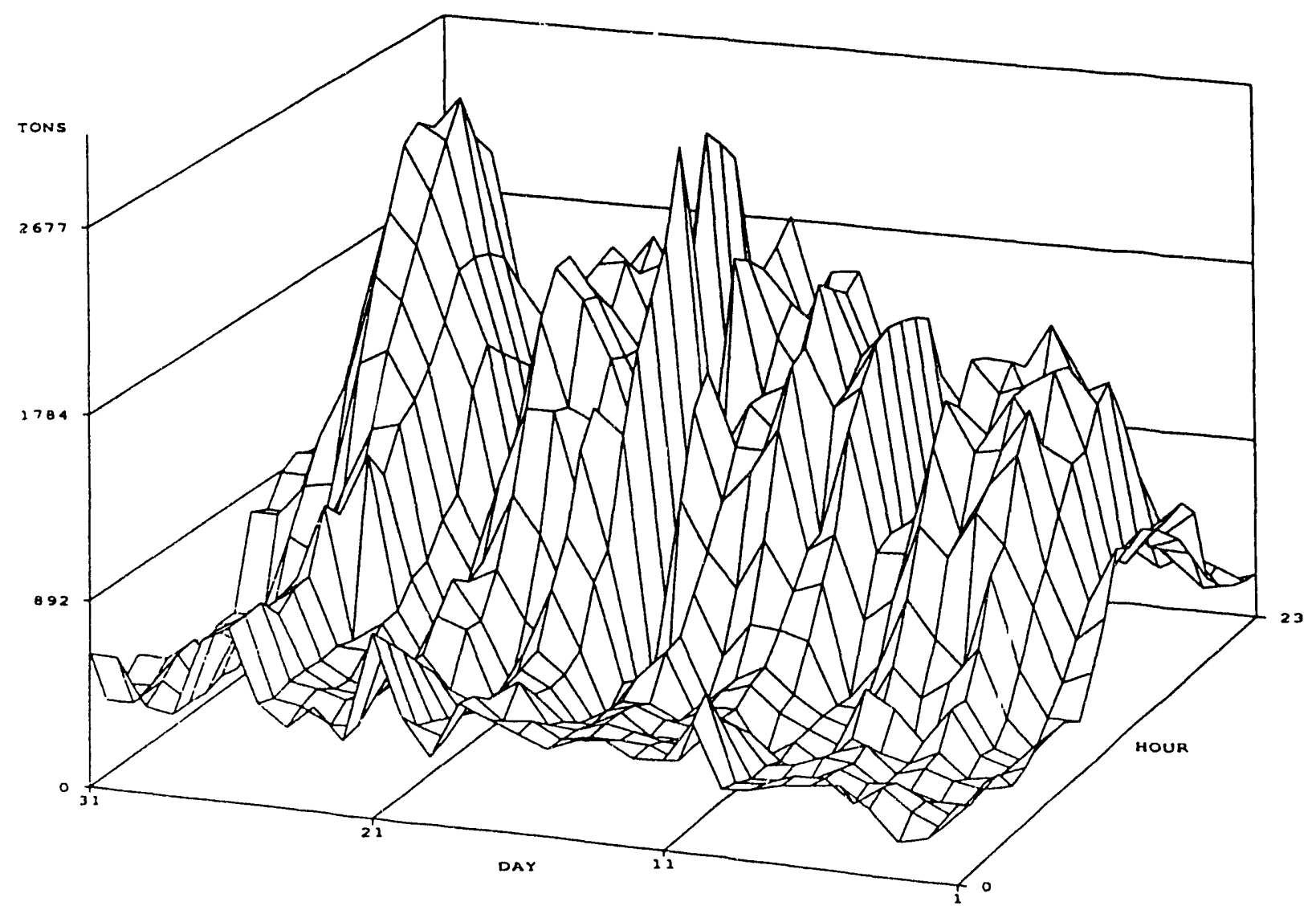


Figure 10. Case Study 1: Electricity Demand by Chiller Compressors (S2+S3) in February 1990

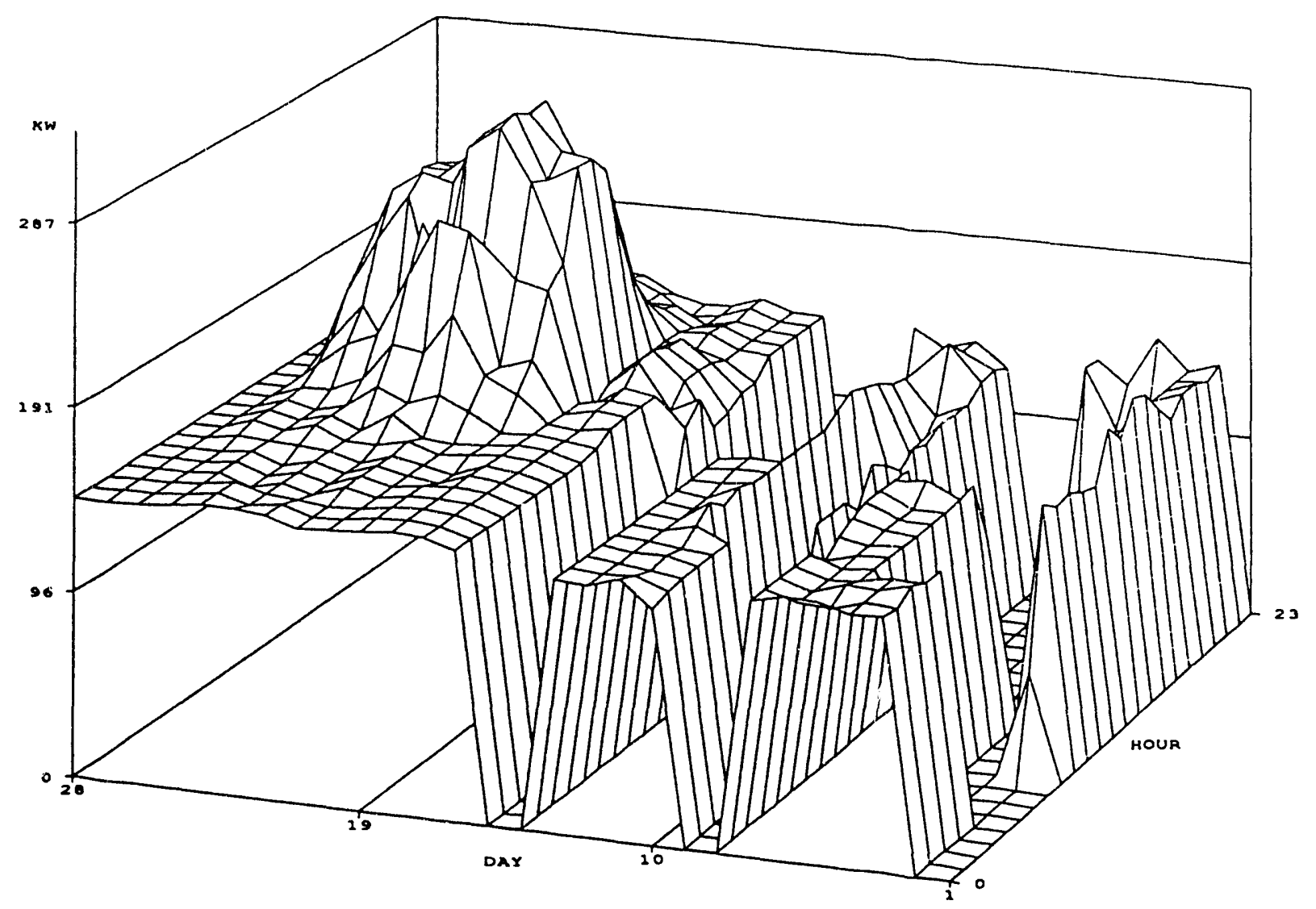

Figure 11. Case Study 1: Electricity Demand by TES Compressors (S1) in February 1990

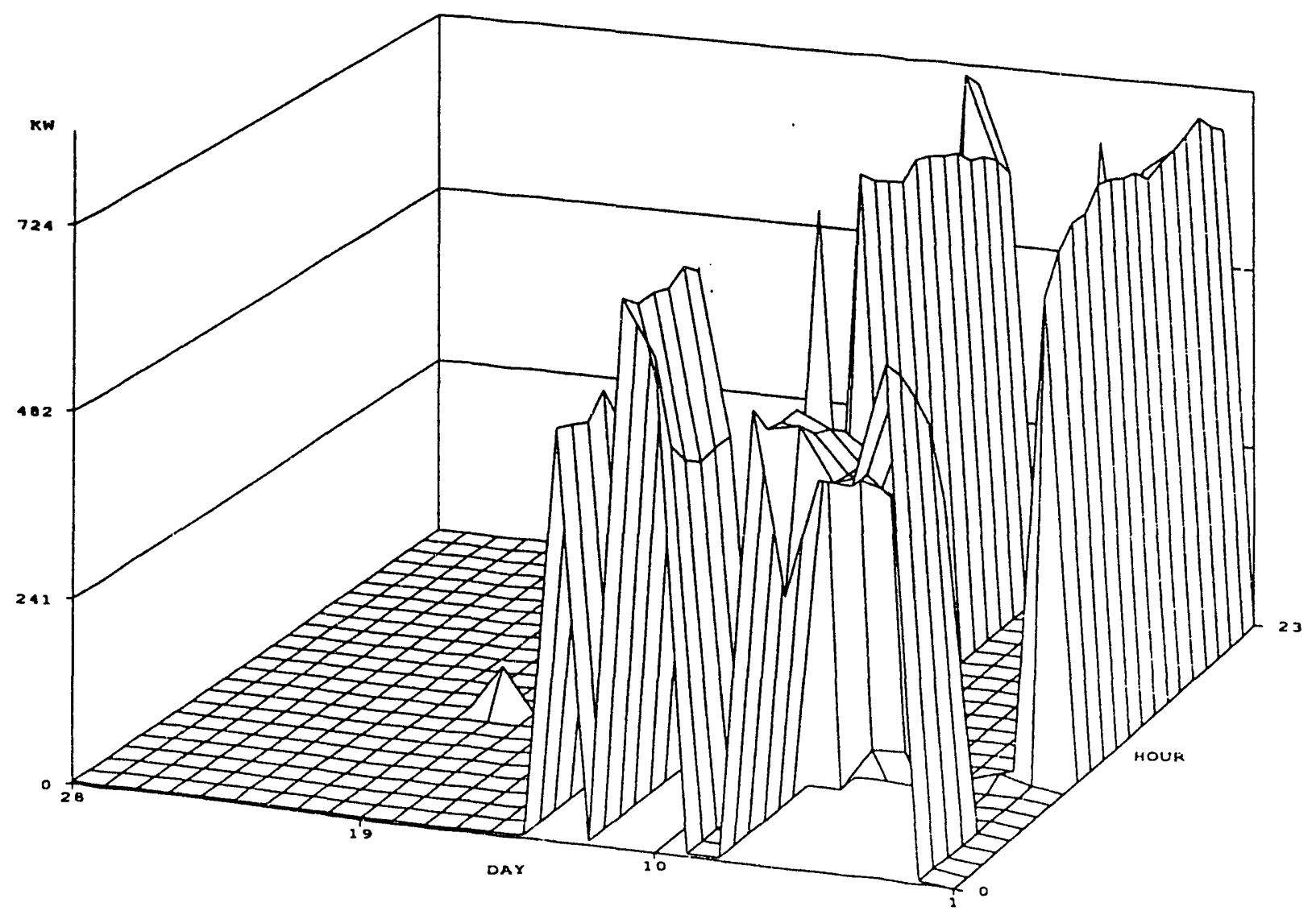


Table 3.

Observed Compressors' COPs at Full Load

\begin{tabular}{|llcl|}
\hline Compressor & Type & COP $^{(1)}$ & Remarks \\
\hline Refrigeration Unit S1 & Screw & $2.38^{(2)}$ & 1250-ton capacity (ice generation mode) \\
Chiller S2 & Centrifugal & 6.0 & 500-ton capacity \\
Chiller S3 & Centrifugal & $6.0^{(3)}$ & 1000 -ton capacity \\
\hline
\end{tabular}

(1) The energy consumption includes the condenser pumps.

(2) This figure was calculated based on the measured rate of ice build-up and energy used by the compressor and ice water pumps and controls. Therefore the COP includes the tank losses. (See Figure 5(1 \& d)-the ice built up at a rate of 750 ton-hour/hr, power consumption for compressors and ice pumps were about $1100 \mathrm{~kW}$ ).

(3) There were calibration problems with the sensors for the electricity measurements; we assumed a COP of 6.0 for chiller S3.

(S3) kicked in during the on-peak hours to meet the cooling loads. Figure 11 shows the activity of the refrigeration compressors (S1) during February. Except for the last week of February, the compressors (S1) worked at night and during the weekends and were off during on-peak hours.

The first week of December 1989 and the fourth week of February 1990 had similar building loads. Starting February 18, the TES system was off-line and the building was cooled with the chillers S2 and S3. Comparing the data for these two weeks, we were able to compare the performance of the TES system (S1) to the conventional chilled water systems (S2 and S3), entirely based on monitored data. Unfortunately, during the summer months there was not a similar instance when the chillers were exclusively used to cool the building. Table 4 shows the breakdown of electricity consumption during the two similar weeks in winter where in one week the TES was used and in the other only the chillers were used to cool the building. Note that the values for TES consumption in February were not zero. This was because they were operating the condenser water pumps while they were maintaining the TES system.

It can be noted in Table 4 that TES system (S1) together with chillers (S2 and S3) consumed almost twice as much energy in the December week as the chillers (S2 and S3) in the February week. The low efficiency of screw-type compressors when they were making ice, the fact that heat exchangers were involved when using the ice, and other heat transfer losses from the tank and piping all contributed to the lower efficiency of the TES system. 
Table 4.

TES System vs. Chilled Water System: Weekly Energy Consumption and Peak Demand.

Average $\mathrm{kW}$ /ton are calculated by dividing the total weekly electricity consumption for systems $\mathbf{S} 1, \mathbf{S 2}$, and $\mathrm{S} 3$ by the total cooling load.

\begin{tabular}{|c|c|c|c|c|c|}
\hline Period & Measurement & $\begin{array}{c}\text { On-peak } \\
\text { 12:00-6:00, } \\
\text { Mon.- Fri. }\end{array}$ & $\begin{array}{c}\text { Part-peak } \\
\text { 8:30-12:00, } \\
\text { 18:00-21:30, } \\
\text { Mon.- Fri. }\end{array}$ & $\begin{array}{c}\text { Off-Peak } \\
\text { All other times }\end{array}$ & Total \\
\hline \multirow[t]{6}{*}{ Dec. 1st week } & Cooling load, 1000 ton-hour & 14.9 & 6.7 & 16.1 & 37.6 \\
\hline & Total building, $M W h$ & 147.7 & 155.0 & 337.4 & 640.1 \\
\hline & TES (S1), MWh & 3.6 & 7.6 & 39.0 & 50.2 \\
\hline & Chillers (S2 and S3), MWh & 2.0 & 1.9 & 8.5 & 12.4 \\
\hline & Peak kW & 6,880 & & & 6,880 \\
\hline & Average $\mathrm{kW} /$ ton & & & & 1.66 \\
\hline \multirow[t]{6}{*}{ Feb. 4th week } & Cooling load, 1000 ton-hour & 14.1 & 7.5 & 16.9 & 38.5 \\
\hline & Total building, MWh & 145.7 & 149.4 & 320.4 & 615.5 \\
\hline & TES (S1), MWh & .6 & .8 & 4.7 & 6.1 \\
\hline & Chillers (S2 and S3), MWh & 10.2 & 5.8 & 12.5 & 28.5 \\
\hline & Peak kW & 5,900 & & & 5,900 \\
\hline & Average $\mathrm{kW} /$ ton & & & & 0.89 \\
\hline
\end{tabular}

For the comparison of TES with conventional chilled water systems, we generated simulated conventional system performance data using the weekly model described earlier. Using the model, the calculation procedure was as follows. The electricity used by the TES compressor (S1), condenser-side pumps, and the exisung chillers (S2 and S3) were deducted from the total building electricity consumption. Then the electricity that would have been required to satisfy the building load using a conventional system was calculated and added to the remainder. This gave an estimate of the total electricity consumption for the building with an assumed conventional system.

Table 5 compares the electricity consumption and savings of the installed TES with the simulated data for the three conventional chiller configurations for the third week of August 1990. On a weekly basis, the TES system, when compared with a single conventional chiller, used 15 and $0.3 \mathrm{MWh}$ less electricity during the on-peak and partial-peak hours, respectively, and $35.8 \mathrm{MWh}$ more during the off-peak hours ( $41 \%$ of the total building off-peak electricity use). The total cooling electricity consumption for the conventional system, however, was $20.6 \mathrm{MWh}$ less (17\% of TES system electricity use). The peak electricity savings of TES was $640 \mathrm{~kW}$. When the TES was compared with the split conventional chillers and twochiller system (one twice the capacity of the other), the peak power savings of the TES system were slightly more, $780 \mathrm{~kW}$ and $660 \mathrm{~kW}$, respectively. But the energy penalties were much higher; the TES system used about 37 to $47 \mathrm{MWh}$ more electricity.

Based on these results, we concluded that it would be unrealistic to assume a single large chiller as a base case for the conventional chiller. By using two chillers to satisfy the building load instead of a single 
chiller, the TES system is shown to be less attractive since the savings during the on peak hours inay not justify the significant losses during the off-peak hours. Note that in Table 5, the most infavorable case for the TES system is the two-chiller system with different chillers sizes. The last line of Table 5 reads: the TES system in this building during this particular week saved 13.5 MWh of electricity during on-peak hours compared to a simulated case where the cooling was met by two conventional chillers; the TES system used 4.9 and 55.8 MWh more electricity during part-peak and off-peak hours, respectively; and during the week TES has reduced the building on-peak demand by $660 \mathrm{~kW}$. For the remainder of this analysis, we decided to use two-chiller system, one with a capacity twice of the other, as a base case for comparisons.

Table 5.

Savings in Electricity Use and Peak Demand Due to the Existing TES

System Compared to Performance of Conventional Chilled-Water System Configurations:

For an Average Week in Summer (third week of August 1990)

\begin{tabular}{|c|c|c|c|c|c|c|}
\hline & \multicolumn{4}{|c|}{ Weekly Elec. Use } & \multicolumn{2}{|c|}{ Building Peak } \\
\hline & $\begin{array}{c}\text { On-peak } \\
\text { 12:00-6:00, } \\
\text { Mon.- Fri. } \\
\text { MWh }\end{array}$ & $\begin{array}{c}\text { Part-peak } \\
\text { 8:30-12:00, } \\
\text { 18:00-21:30, } \\
\text { Mon.- Fri. } \\
\text { MWh }\end{array}$ & $\begin{array}{c}\text { Off-Peak } \\
\text { All other times }\end{array}$ & Total & On-peak & 24-hour \\
\hline $\begin{array}{l}\text { Measured Data } \\
\text { TES System }\end{array}$ & 13.1 & 21.7 & 87.0 & 121.8 & 6,330 & 6,340 \\
\hline & \multicolumn{4}{|c|}{ Weekly Savings } & \multicolumn{2}{|c|}{ TES Peak Reduction } \\
\hline $\begin{array}{l}\text { Simulation } \\
\text { Single Chiller } \\
\text { Split Chiller } \\
\text { Two Chillers }\end{array}$ & $\begin{array}{l}15.0 \\
16.9 \\
13.5\end{array}$ & $\begin{array}{r}0.3 \\
-3.5 \\
-4.9\end{array}$ & $\begin{array}{l}-35.8 \\
-51.0 \\
-55.8\end{array}$ & $\begin{array}{l}-20.5 \\
-37.6 \\
-47.2\end{array}$ & $\begin{array}{l}640 \\
780 \\
660\end{array}$ & $\begin{array}{l}630 \\
770 \\
650\end{array}$ \\
\hline
\end{tabular}

(1) One chiller twice the size of the other

In the remainder of this section we will try to quantify the performance of the TES system at hand. A qualitative analysis of the available data showed that the building loads were quite dependent on the season as opposed to buildings where the intemal loads are the major factor characterizing the load profile. During June and August 1990, loads were quite similar and they were usually at the level of 2,000 tons. Higher loads were observed in September. In winter there were occasional warm weeks when there were substantial cooling loads but otherwise cooling loads were low. We selected one example for each of the following situations: (1) a warm week in winter, (2) a typical week in August, and (3) a warm week in September.

Simulations of conventional chilled water systems for the above selected weeks, using the two-chiller conventional system configuration, were performed and the results are given in Table 6. This table also includes similar figures representing the difference between the monitored data for two warm weeks in winter presented in Table 4. The similarity between the figures on the first and second rows indicates the 
level of accuracy of the simulation procedure employed. The results in Table 6 are given in such a fashion that different electricity price schedules can be applied to them to estimate the dollar savings.

Table 7 shows the measured electricity use by the TES system for the three selected weeks. This table is presented so that we can compare the design intentions to the measured performance of the system. The designers estimated that the TES system would reduce the cooling demand of the building during on-peak hours by $55 \%$. The actual system does better than that by reducing cooling demand by $65 \%$ (See Tables 10 and 11: $900 /(900+474)$ ) in September and 55\% in August. During the warm week in winter, demand is reduced by $39 \%$. The designers also predicted a shift of more than half of the on-peak cooling electricity needs to off-peak hours. In September this shift was 65\%; in August, it was 50\%; and during the warm week in winter, this shift was $42 \%$.

Table 6.

Savings in Electricity Use and Peak Demand

Due to the Existing TES System Compared to a Conventional System

\begin{tabular}{|c|c|c|c|c|c|c|}
\hline & \multicolumn{4}{|c|}{ Energy Savings } & \multicolumn{2}{|c|}{ TES Peak Reduction } \\
\hline & $\begin{array}{c}\text { On-peak } \\
\text { 12:00-6:00 } \\
\text { Mon.- Fri. } \\
\text { MWh }\end{array}$ & $\begin{array}{c}\text { Part-peak } \\
\text { 8:30-12:00 } \\
\text { 18:00-21:3 } \\
\text { Mon.- Fri. } \\
\text { MWh }\end{array}$ & $\begin{array}{l}\text { Off-Peak } \\
\text { other tir }\end{array}$ & Total & On-peak & 24-hour \\
\hline $\begin{array}{l}\text { Measured Data } \\
\text { Performance data calculated } \\
\text { from two weeks of Monitored } \\
\text { Data in Winter } \\
\end{array}$ & 4.6 & -3.6 & -35.0 & -34.0 & $?$ & $?$ \\
\hline $\begin{array}{l}\text { Simulations } \\
\text { A Warm Week in Winter }{ }^{(2)} \\
\text { A Typical Week in August } \\
\text { A Warm Week in September } \\
\text { (4) }\end{array}$ & $\begin{array}{r}4.0 \\
13.5 \\
20.5\end{array}$ & $\begin{array}{r}-3.1 \\
-4.9 \\
0.6\end{array}$ & $\begin{array}{l}-30.2 \\
-55.8 \\
-40.0\end{array}$ & $\begin{array}{l}-29.3 \\
-47.2 \\
-18.9\end{array}$ & $\begin{array}{r}90 \\
660 \\
900\end{array}$ & $\begin{array}{r}90 \\
650 \\
900\end{array}$ \\
\hline
\end{tabular}

(1) 4th week of February 1990 and 1st week of December 1989

(2) 1 st week of December 1989

(3) 3rd week of August 1990

(4) 4th week of September 1990

? Not Available 
Table 7.

TES System Electricity Use and Building Peak Demand

\begin{tabular}{|c|c|c|c|c|c|c|c|c|}
\hline & \multicolumn{4}{|c|}{ TES Electricity Use } & \multicolumn{2}{|c|}{ Building Peak } & \multirow[t]{2}{*}{$\begin{array}{l}\text { TES Elec. } \\
\text { at Peak }\end{array}$} & $\begin{array}{c}\text { Total Cooling } \\
\text { Load }\end{array}$ \\
\hline & $\begin{array}{l}\text { On-peal } \\
12: 00-6: 0 \\
\text { Mon.- Fr } \\
\text { MWh }\end{array}$ & $\begin{array}{l}\text { Part-pea } \\
\text { :30-12: } \\
: 00-21 \text { : } \\
\text { Mon. F } \\
\text { MWh }\end{array}$ & $\begin{array}{l}\text { Off-Peal } \\
\text { All othe } \\
\text { times } \\
\text { MWh }\end{array}$ & Total & On Pea & 24-hour & & 1000 ton-hours \\
\hline Measured Data & & & & & & & & \\
\hline A Warm Week in Winter ${ }^{(1)}$ & 5.6 & 9.5 & 47.5 & 62.5 & 6879 & 6879 & 141 & 37.6 \\
\hline A Typical Week in August ${ }^{(2)}$ & 13.1 & 21.7 & 87.0 & 121.8 & 6330 & 6340 & 552 & 125.5 \\
\hline A Warm Week in September ${ }^{(3)}$ & 10.5 & 20.5 & 78.7 & 109.7 & 6000 & 6000 & 474 & 158.8 \\
\hline
\end{tabular}

(1) 1st week of December 1989

(2) 3rd week of August 1990

(3) 4 th week of September 1990

Some general observations from Tables 10-11 can be made. (1) For each saved $\mathrm{kWh}$ during the on-peak period, at least twice as much energy was spent to meet the load by the TES system. This was mostly because of the lower COP of the ice-building refrigeration units and the heat transfer losses in the heat exchangers, pipes, and tanks. (2) The TES system used less energy during the week in September when loads were higher than the week in August. This probably stemmed from the fact that during September the nighttime outdoor temperatures were lower, resulting in a lower lake temperature and, hence, an increased system efficiency.

During high cooling demand in the warm week in September, the TES system seemed to have saved about $900 \mathrm{~kW}$ during on-peak periods at the cost of $18.9 \mathrm{MWh}$ increase in electricity consumption. On the other hand, in a typical summer week (as in August), the TES savings were not as high. The peak demand reduction was $660 \mathrm{~kW}$ and the increase in energy consumption was $47.2 \mathrm{MWh}$ per week. Although during the typical summer weeks, the TES system had significant energy penalties when compared to optimally designed conventional systems, the peak electricity savings justified the use of the TES. As it can be seen from Table 8, the dollar savings of the TES systems were mostly due to peak reduction: consumption shift did not yield any savings. For the rate schedule used (PG\&E E-20s), the TES system saved twice as much money on a hot day than on an average summer day. It can also be seen in Table 8 that in winter, for this particular building and for the rate schedule used, there were no dollar savings even on a warm day.

\section{Summary}

Except for some problems related to the maintenance and expansion of the system, TES has been successfully employed in this building. The peak demand savings realized by the use of the TES system were better than predicted for a peak day. For an average summer day, the savings were also quite good given 
Table 8.

Dollar Savings in Electricity Use and Demand Charges Due to the TES

System Compared to a Conventional System Under Different Load Scenarios

(Estimates of savings are based on PG\&E's E-20 rate schedule.)

\begin{tabular}{|c|c|c|c|c|c|c|}
\hline & \multicolumn{4}{|c|}{$\begin{array}{l}\text { Weekly Savings due to } \\
\text { Energy Savings }\end{array}$} & \multicolumn{2}{|c|}{$\begin{array}{l}\text { Monthly Savings due to } \\
\text { Peak Reduction }\end{array}$} \\
\hline & $\begin{array}{l}\text { On-peak } \\
\text { 12:00-6:00 } \\
\text { Mon.- Fri }\end{array}$ & $\begin{array}{l}\text { art-pea } \\
\text { 30-12: } \\
\text { O0-21: } \\
\text { Ion.- F }\end{array}$ & $\begin{array}{l}\text { Off-peak } \\
\text { other tir }\end{array}$ & Total & On-peak & 24-hour \\
\hline & $\$$ & $\$$ & $\$$ & $\$$ & $\$$ & $\$$ \\
\hline Warm Week in Winter ${ }^{(I)}$ & 230 & -163 & $-1,544$ & $-1,477$ & 846 & 297 \\
\hline Average Week in August ${ }^{(2)}$ & 1,326 & -326 & $-2,850$ & $-1,850$ & 6,204 & 2,178 \\
\hline Warm Week in September ${ }^{(3)}$ & 2,006 & 42 & $-2,042$ & 6 & 8,460 & 2,970 \\
\hline
\end{tabular}

(1) 1 st week of December 1989

(2) 3rd week of August 1990

(3) 4 th week of September 1990

the current electricity rate schedules. For warm days in winter, the system did not do better than a conventional system partly because of the rate schedule and partly because of the fact that much of the equipment operated at part-load conditions. But overall, the losses incurred during the limited number of warm weeks in winter were more than compensated for by the savings during the summer season.

The problems encountered in this building were:

\section{Design Related}

When the building and systems were being designed, the future increases in intemal loads mostly due to the increased use of office equipment were not anticipated. The equipment layout was not suitable for expansion of the system; when a new chiller was added it had to be placed in the garage. The layout of the equipment also caused some operational problems.

The system is confronted with a severe capacity limitation on the condenser-side. There are problems with the lake used to remove heat. The temperature dynamics of the lake have not been accurately modeled and the drought has caused filtration problems. Because of the space and configuration limitations, the owners are rightfully reluctant to add cooling towers to the system which would remedy the condenser-side bottleneck. Another major problem related to this TES is that it is not possible to use all of the ice capacity and this causes problems during warm summer days.

The system was not designed to permit isolation of certain sections of the system for extended maintenance periods. Such arrangements had to be designed and installed later on. 
The HVAC system and the TES system are controlled by different control systems. This in a way prevents implementation of a sensible control strategy.

\section{Installation Related}

Very limited performance testing was performed at the acceptance stage.

\section{Operation Related}

The refrigeration systems was never operated in the intended dual operating mode: nighttime ice-making, daytime chilled water-producing. To make up for the daytime shortage of chilled water, another chiller had to be added for daytime operation.

Building operators have to go through unconventional procedures to measure the refrigerant level in the system and to maintain the oil levels in the compressors. These problcms are a product of improper layout of the equipment.

\section{Maintenance Related}

One of the major problems the TES system is currently encountering is the lack of quality service and spare parts from the equipment manufacturers. Some of the equipment were custom built and some suppliers of the equipment are out of business.

A significant number of cut-off valves had to be installed later on in order to be able to isolate certain sections of the equipment while the rest was operating to facilitate extended maintenance.

The equipment, especially the TES equipment, was not installed with enough sensors to monitor performance and to facilitate proper control. The building operators used PG\&E's monitored data to assess the TES performance. Calibration procedures for the existing sensors were arbitrary, which made understanding the collected data extremely difficult.

The quality of the materials used to build the equipment was not satisfactory as in the case of cracked weldings on the evaporator. 


\section{Chapter 3}

\section{Case 2: A 24-Story Office Building in San Francisco}

\section{Background}

This building is another one of the 12 buildings that were monitored by PG\&E for TES system performance evaluation. In 1984, the design engineers of the TES system published their work, documenting the initial design expectations and their intentions [11]. The building was studied by LBL staff in 1987 [5]. Even though the owners and building engineers have changed several times since the building was completed, we obtained fairly reliable information on the building performance and modifications made to the HVAC system during the 1987-1989 period.

This building was chosen for this analysis because of availability of historical data and because of the building type-a high-rise office is an important building type for TES application.

We contacted the building owner in September 1990 and discovered that the building has changed ownership since 1987. The new owners were unsatisfied with the performance of the building environmental systems and were retrofitting the HVAC system. We contacted the chief engineer of the managing company and visited the building on November 13, 1990, to interview the director of engineering of the managing company and the chief building engineer. Unfortunately, the building owners did not grant us permission to acquire recent data from PG\&E.

With this case study, we add an account of recent activities in the building's history first published by Piette [5]. We expand on the events discussed in that report and extend and refine that analysis to quantify the merits of TES systems compared to conventional chilled water systems.

\section{Building System Design and Description}

This 265,000 $\mathrm{ft}^{2}, 24$-story San Francisco office building was built in 1982. TES was chosen based on a feasibility study which concluded that a partial ice storage system would have first-costs below conventional cooling systems. The electricity costs would also be reduced because of time-of-day rates and demand charges in the electricity tariff. The TES was designed for partial storage on a peak day.

During the design phase, the peak load for this building was determined to be 460 tons and the peak daily cooling requirement to be 3300 ton-hours. A 137.5 ton refrigeration plant operating 24 hours a day would supply the design refrigerating requirements. Since during the day the capacity would be used to meet the building cooling loads for at least 10 hours, the storage capacity was designed to be enough to take care of the remaining daytime loads and was sized to be 1925 ton-hours. The additional storage capacity of some of the equipment (coils, pumps, heat exchangers) was not directly considered in the sizing but was considered as a protection against higher-than-predicted loads.

In order to build in redundancy and also to reduce electric demand, the decision was made to split the nominal load between two equally sized and fully independent refrigeration and storage circuits. This 
resulted in two systems, each with 70 ton refrigeration and 960 ton-hour storage capacities. The central plant configuration is given in Figures 12 and 13.

Reciprocating, open, industrial quality refrigerating compressors were specified. Due to considerations of safety, R-22 refrigerant was specified instead of R-717 (ammonia) even though the latter is considerably cheaper. The refrigeration design conditions were based on $0.5 \%$ wet-bulb $\left(63^{\circ} \mathrm{F}\right)$ in San Francisco, allowing a maximum condensing temperature of $90^{\circ} \mathrm{F}$ on the average $23^{\circ} \mathrm{F}$ suction temperature that the ice builder was designed for. At these operating conditions, the compressor had a rated COP of 4.95 and this was judged to be adequate from an energy point of view when compared to centrifugal refrigeration. A suction accumulator/heat exchanger refrigerant system was chosen over a pumped overfeed-nonexpansion valve system. In the designed system, the liquid leaving the condenser was routed through a heat exchanger, which was surrounded by the suction gases on their way to the compressor. This design avoided the use of refrigerant circulating pumps and reduced the first cost.

The factory-packaged ice builders consist of 1-1/4 inch steel pipe evaporator surface immersed in insulated open tanks. Ice is built on the outside of these 1-1/4 inch pipes and also on the surfaces that form baffles to circuit water as it flows through the tank. A controlled path unit avoids the need for an agitation system that lead to savings in first costs and operating costs. This system would also require less maintenance. The 960 ton-hour storage requirement was reached by building up approximately two inches of ice on the evaporator's primary surface and on the baffles. The use of the controlled water path unit facilitated the use of the coldest water that can be supplied from the ice builders. Water is circulated from the open ice-builder tanks through the heat exchangers and is returned to the ice builders.

Water-cooled condensers were selected to permit rejection of the design load at a $90^{\circ} \mathrm{F}$ saturated discharge temperature. This resulted in a nominal 130-ton condenser on each of the 70-ton chillers. The increased condenser surface helped to keep the head pressure and the horsepower requirements low. The oversized condensers were necessary due to the difficulties in matching loads with the equipment available in the market. Cooling towers were also sized down to 137.5 tons instead of the 460 tons that would be required for a conventional plant configuration.

A single-duct variable-air-volume (VAV) system was installed, with air-handling units on each floor. The air-handling units were down-sized. Most of the units were four-row cooling coils with a $5.6 \mathrm{~kW}$ motor, as opposed to six-row cooling coils and a $7.5 \mathrm{~kW}$ motor in a conventional system. Very cold, $38^{\circ} \mathrm{F}$ water was to be supplied by the system. The air pressure drop across the cooling coils was reduced from 0.82 inches $\mathrm{H}_{2} \mathrm{O}$ in the conventional chilled water system to 0.18 inches $\mathrm{H}_{2} \mathrm{O}$ in the system using storage.

The complete HVAC and plumbing system for this project cost $\$ 2.4$ million (about $\$ 9 / \mathrm{ft}^{2}$ ). The icestorage system was estimated to cost $\$ 22,000$ less (less than $1 \%$ ) than a conventional system using centrifugal chillers. Furthermore, reduced sizing requirements for fans, pumps, and compressors saved an estimated $\$ 60,000$ in first cost (for a total first cost savings of $-3.4 \%$ ).

The ice-storage plant was estimated to reduce cooling electricity demand by $60 \%$ over a conventional system. This estimate included the cooling tower fans, condenser water pumps, and compressors. Electricity savings were estimated to total $\$ 38,000$ per year based on the PG\&E rates schedules in use during the time of construction and in the early years of operation. As originally designed, the system was to be 
Figure 12. Case Study 2:

Chilled Water Loop of the Central Plant

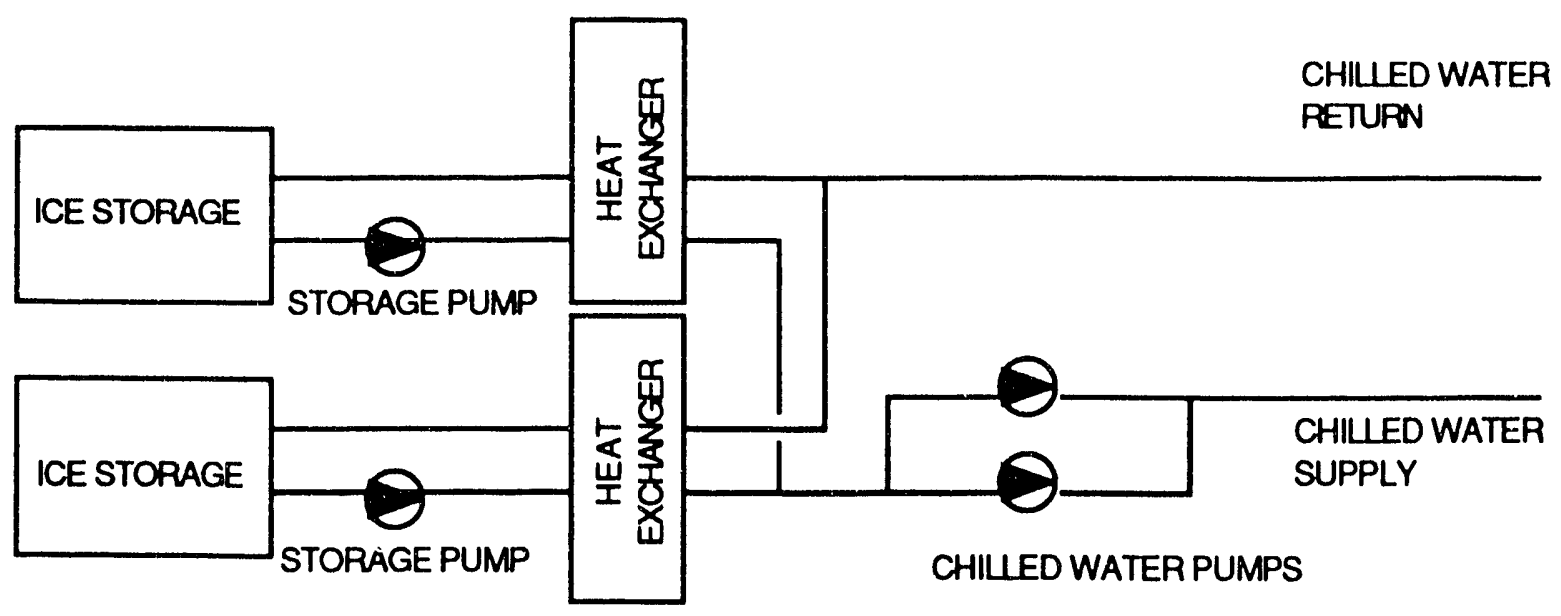

Figure 13. Case Study 2:

Refrigerant Loop of the Central Plant

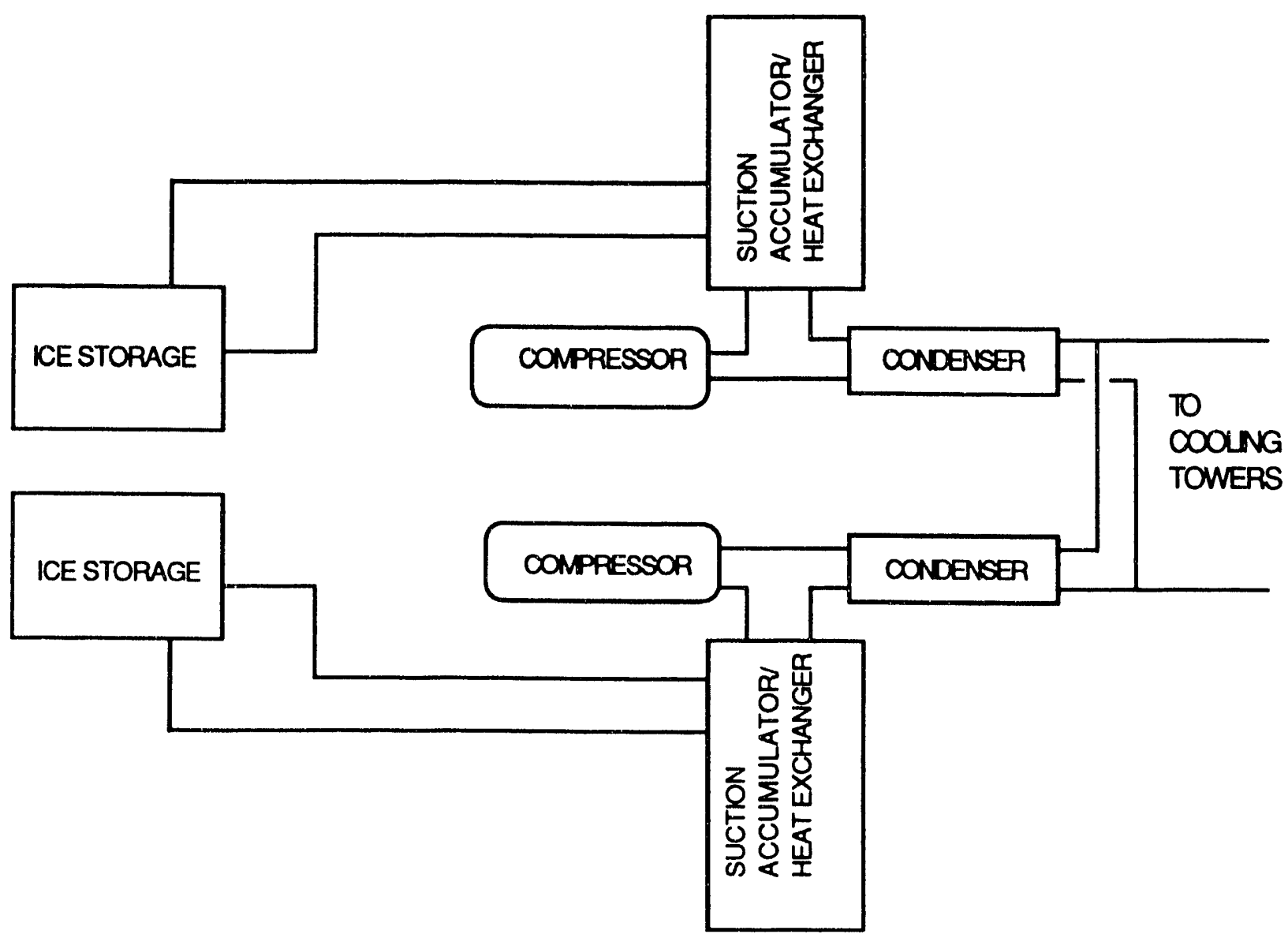


controlled on a design day as follows. Ice was to be built during non-peak hours unless the ice thickness sensors indicated a full range. During on-peak hours, the cooling capacity would be directly absorbed by the building. To do this, the compressors will have had to work non-stop for 24 hours. The designers did not mention an intended control strategy for typical, non-design days operation.

\section{Operation History}

In 1987, the building changed hands and the new owners performed a detailed audit, identified problems, and developed a preventive maintenance program. At about the same time, PG\&E started monitoring the building for TES performance. During the same year, a variety of indoor comfort and environmental parameters were measured for a winter and a summer period as part of a study sponsored by the American Society of Heating Refrigeration and Airconditioning Engineers (ASHRAE). At that point it was clear that the building owners and operators were confronting serious problems in operating and maintaining the system.

During 1987, the computerized data acquisition system installed by PG\&E collected data at 15-minute intervals. Measurements were taken for the electric demand of the two compressors, chilled-water pump, whole-building electric demand, and delivered thermal cooling to the building. The condenser pumps and fans were not separately metered.

The system could not maintain adequate indoor comfort; the loads exceeded the system's capabilities. This conclusion was based on data describing the building's indoor thermal environment from a coincidental study sponsored by ASHRAE [13].

The new owner assumed management of the property in April 1987. Under the new ownership, it was noted that the system frequently failed by mid-aftemoon and rarely maintained an acceptable comfort level for the occupants. Two years were spent analyzing the system and performing numerous corrective measures to enhance the system.

The initial objective was to inventory and physically inspect all of the mechanical equipment in the building to assess its condition and to develop a computer-based preventive maintenance program for the systems. The initial findings, however, determined that extensive work would have to be performed throughout the system before a regularly scheduled preventive maintenance program could be undertaken.

The problems confronted in this building and actions taken to remedy them are described below.

\section{Central Plant}

After operating non-stop since construction, the system was found to be over-taxed and under-maintained. There were repeated problems with bridging of the ice fields and compressor failure due to wildly fluctuating head pressures. Ice thickness controls had been disconnected and there were indications that the ice-storage units were over-charged and contaminated with oil. As a result, the compressors were unable to recharge the storage units, which typically completely melted down by mid-aftemoon. Coupled with the conditions outlined below, the building frequently overheated causing considerable discomfort to its occupants. In September 1987, the following corrective actions were taken: (1) purged each system of 
refrigerant, oil, and water, removed construction debris from the ice-storage units, and attempted to remo'ic excessive oxidation on the evaporator tubes and plates, (2) overhauled the compressors, heat exchangers, and pumps as required, (3) added conventional oil separators to the existing recovery system and liquid refrigerant receivers to allow for load fluctuations and storage for maintenance; added water regulating valves to elevate and stabilize head pressures; reactivated the ice thickness controls and added liquid line selenoid valves at each quadrant of the ice-storage units to minimize bridging; added a water filtration and treatment system along with expansion tanks. (Prior practice of replenishing the water side of the system called for city water via a garden hose.)

It was discovered that due to the location of the cooling tower in a recessed well covered bv catwalks, back-draft was creating a short-cycling of the cooling tower fans, thereby compromising the heat rejection system. In June 1988, the catwalk grating from above the cooling tower was removed resulting in an increase in the rate of heat rejection. At that time, it was also noted that future plans should call for installing a plume or metal collar to parapet height to further alleviate back-draft problem.

It was determined that the manual expansion valves in the ice storage units were not delivering enough refrigerant to the ice files. In October 1988, the manual valves were replaced with thermal expansion valves.

\section{Air Handlers}

All air handlers were found to be in very poor conditions with evidence of years of deferred maintenance largely due to their inaccessible locations in the ceiling plenum over the restrooms. Access was restricted to 16" square access hatches; in some cases, large portions of sheet rock ceilings had to be dismantled for inspection and maintenance purposes. Filters had disintegrated, fan belts and armatures were disconnected, and outside dampers were frozen in place-some in a completely closed position. In November 1987, the following corrective actions were taken: (1) performed complete maintenance on each unit including changing the filters, balancing the water across the coils, reactivating controls and dampers; and (2) replaced all $5.0 \mathrm{hp}$ fan motors with energy-efficient $7.5 \mathrm{hp}$ motors and resheaved the fans accordingly.

\section{Controls}

Only pneumatic controls were initially installed in the building; most controls were found to be defective or by-passed. In December 1987, the building and installation of pneumatic control panels on each floor, which included running over four miles of pneumatic tubing to new thermostats and controls, was begun. Panels were designed to modulate and control duct and floor static pressure.

\section{Distribution Equipment}

Distribution of air was designed to be achieved through light troffers. Sheet metal plenums were connected to selected light fixtures. However, due to the location of the junction box on each light fixture, the plenums were not fastened properly, allowing vast quantities of air to escape into the ceiling plenums. In other cases, flexible ductwork was found to be disconnected altogether. In April 1988, approximately 600 light troffers were replaced with new supply air ceiling diffusers and each floor was rebalanced.

It was determined that the supply air dampers were undersized on the most of the floors. In April 1989, it was planned to enlarge certain of the outside supply air dampers. 
As a result of these modifications, energy use in 1988 was slightly lower than energy use in 1987 [5]. Total annual electricity costs were reduced by $9 \%$. During the winter of 1988-1989, the system modifications were successful in shifting compressor use to full-storage mode: at no time were the compressors on during on-peak periods and electricity costs were expected to be further reduced. Unfortunately, for that period, we do not have accurate information on the comfort conditions in the building.

In 1990, the building changed hands again. When visiting the building, we found out that the new owners were assessing the situation and planning radical retrofits. Their complaints and problems were:

1. The system was undersized. More ice storage capacity was needed. Eleven-hour working days were not uncommon in San Francisco, and on such days the operators received a lot of occupant complaints. The new thermal expansion valves work for $12^{\circ} \mathrm{F}$ superheat. In the early years of this building, the owners probably had replaced thermoelectric expansion valves with manual expansion valves to remedy such situations. Wetted evaporator surfaces have increased the performance of the system but have also caused pressure fluctuations resulting in compressor failures.

2. There were no provisions for maintenance. There was no backup ice storage capacity to facilitate extended maintenance periods. Access to certain sections of the ice tanks was impossible without cutting an access area every time repairs were needed.

3. The ice was built unevenly in the tanks. This in turn prevented them obtaining water at design temperatures from the heat exchangers.

The new owners had decided to add a 300-ton chiller to the system. With the new chiller, the operating schedule would be such that the new chiller would work as the lead. During peak hours, the chiller would be turned off and ice would be melted to cool the building. Fortunately, the cooling tower and the condenser were oversized at the design phase and new capacity at that end was not needed.

There were also plans for installing a control system to the central plant during 1992. Currently, all systems are controlled manually.

\section{Analysis of Measured Data}

We obtained hourly submetered data for this building for the period of February 1987 to June 1987. The data comprised the total electricity consumption, the total building thermal load, electricity used by the refrigerator compressor, and electricity used by the chilled water pump. Our attempts to get permission from the owners to obtain more recent data collected by PG\&E were unsuccessful.

Piette compared the performance of the TES system to a case where the building cooling loads were met by a single chiller with enough capacity to meet the design peak condition [5]. With the electricity price schedules in that time period, the TES saved in winter and lost money in the summer. Since data were not available for the whole year, net annual savings were not determined. The savings were by no means even close to what was anticipated by the designers. For the five months examined, the savings were calculated to be approximately $\$ 1,500$ as opposed to the estimated $\$ 38,000$ yearly savings. In the same study, electricity consumption was binned into months and time of the day (on-peak, part-peak and off- 
peak) for evaluating savings (similar to analysis in this study, based on one large chiller with partial load curve applied every hour).

As in Case 1, we analyzed the data w'eek by week. We first screened the data to select weeks that would represent periods with different characteristics. This way we could have an idea of what the overall situation would be by putting together the representative weeks. The data for the five months examined were complete. The analysis of the data revealed that during the later months the performance of the system deteriorated. This period corresponded to the time when the owners were complaining about contamination of the tanks and an overcharging system. Since we were trying to quantify the merits of TES from design and operations point of view, we were left only with data for earlier months of 1987 . The data were not sufficient to quantify the effect of maintenance issues on operating costs.

Figures 14-17 depict the building cooling load and compressor activity for the months February 1987 and June 1987. It can be seen that the third week of February and the third week of June are similar as far as the building thermal cooling loads are concerned. During these weeks, the total load for the building was roughly 9000 ton-hours in each case. As it can be seen in Table 9 there was more load in the third week of February during the on-peak period than the similar period in the third week of June. Figures 15 and 17 show the way the refrigerator compressors were employed. Note that the compressors were not operated during the on-peak hours during the third week of February. During the third week of June, the compressors were operated.

Table 9.

TES System Performance During Summer and Winter: Weekly Energy Consumption and Peak Demand Average $\mathrm{kW} /$ ton are calculated by dividing the total weekly electricity consumption for the TES system by the total cooling load.

\begin{tabular}{|c|c|c|c|c|c|}
\hline Period & Measurement & $\begin{array}{l}\text { On-peak } \\
\text { 12:00-6:00, } \\
\text { Mon.- Fri }\end{array}$ & $\begin{array}{l}\text { Part-peak } \\
\text { 8:30-12:00, } \\
\text { 18:00-21:30, } \\
\text { Mon.- Fri. }\end{array}$ & $\begin{array}{l}\text { Off-Peak } \\
\text { All other times }\end{array}$ & 24-hour \\
\hline \multirow[t]{6}{*}{ June 1987 3rd week } & Load 1000 ton-hour & 4.5 & 3.1 & 1.5 & 9.1 \\
\hline & Total Building MWh & 32.2 & 30.9 & 52.1 & 115.2 \\
\hline & Pumps MWh & 0.6 & 0.6 & 0.4 & 1.6 \\
\hline & Compressors MWh & 3.8 & 4.0 & 8.8 & 16.6 \\
\hline & Peak kW & 1,110 & & & 1,110 \\
\hline & Average $\mathrm{kW} /$ ton & & & & 2.01 \\
\hline \multirow[t]{6}{*}{ Feb. 1987 3rd week } & Load 1000 ton-hour & 5.3 & 3.4 & .3 & 9.0 \\
\hline & Total Building MWh & 28.0 & 28.9 & 46.4 & 103.3 \\
\hline & Pumps MWh & 1.2 & 1.0 & 0.1 & 2.3 \\
\hline & Compressors MWh & 0.8 & 3.4 & 5.6 & 9.8 \\
\hline & Peak kW & 1,130 & & & 1,130 \\
\hline & Average $\mathrm{kW} / \mathrm{ton}$ & & & & 1.33 \\
\hline
\end{tabular}


Figure 14. Case Study 2: February 1987 Cooling Load

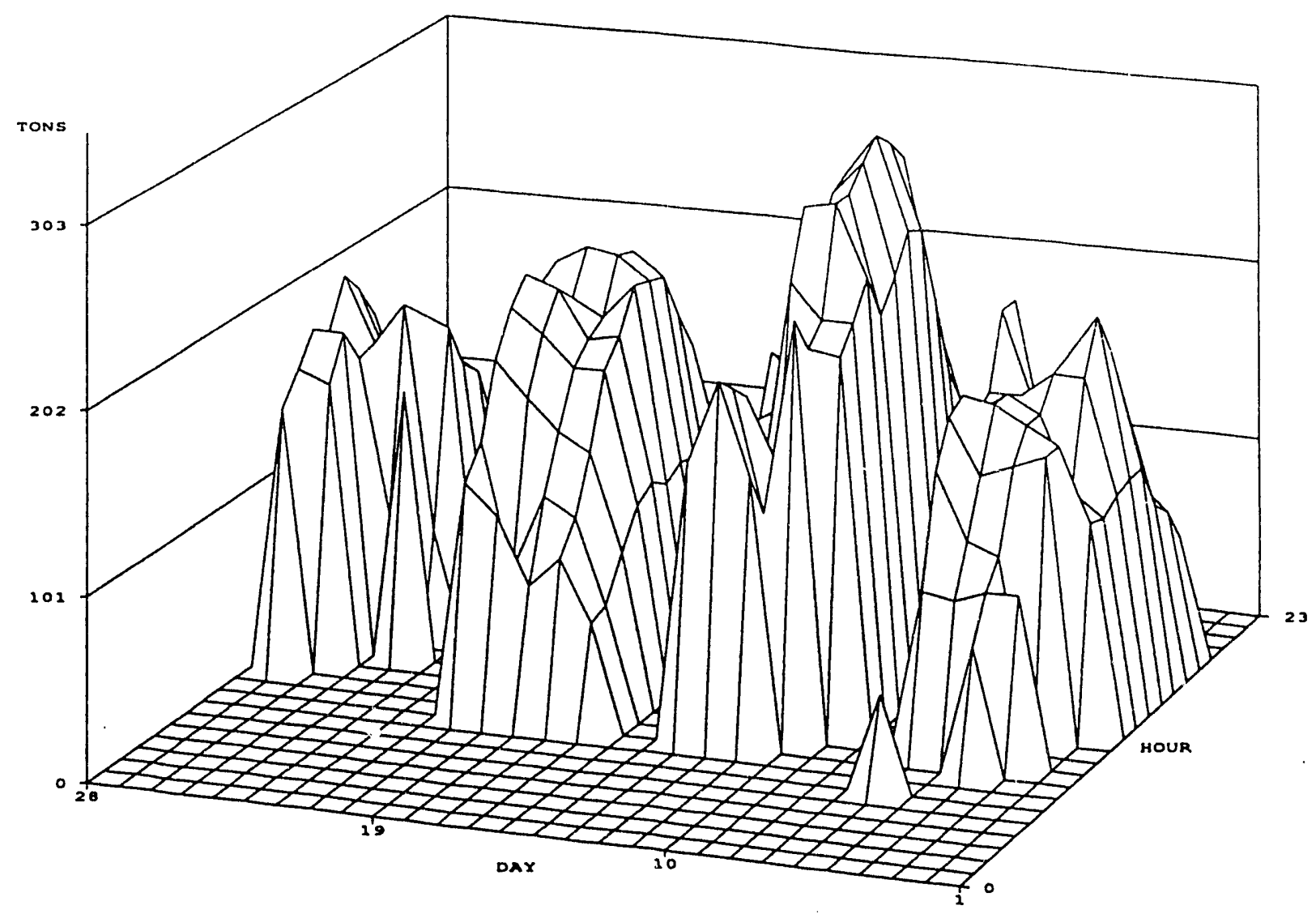

Figure 15. Case Study 2: Electricity Demand by TES Compressors in February 1987

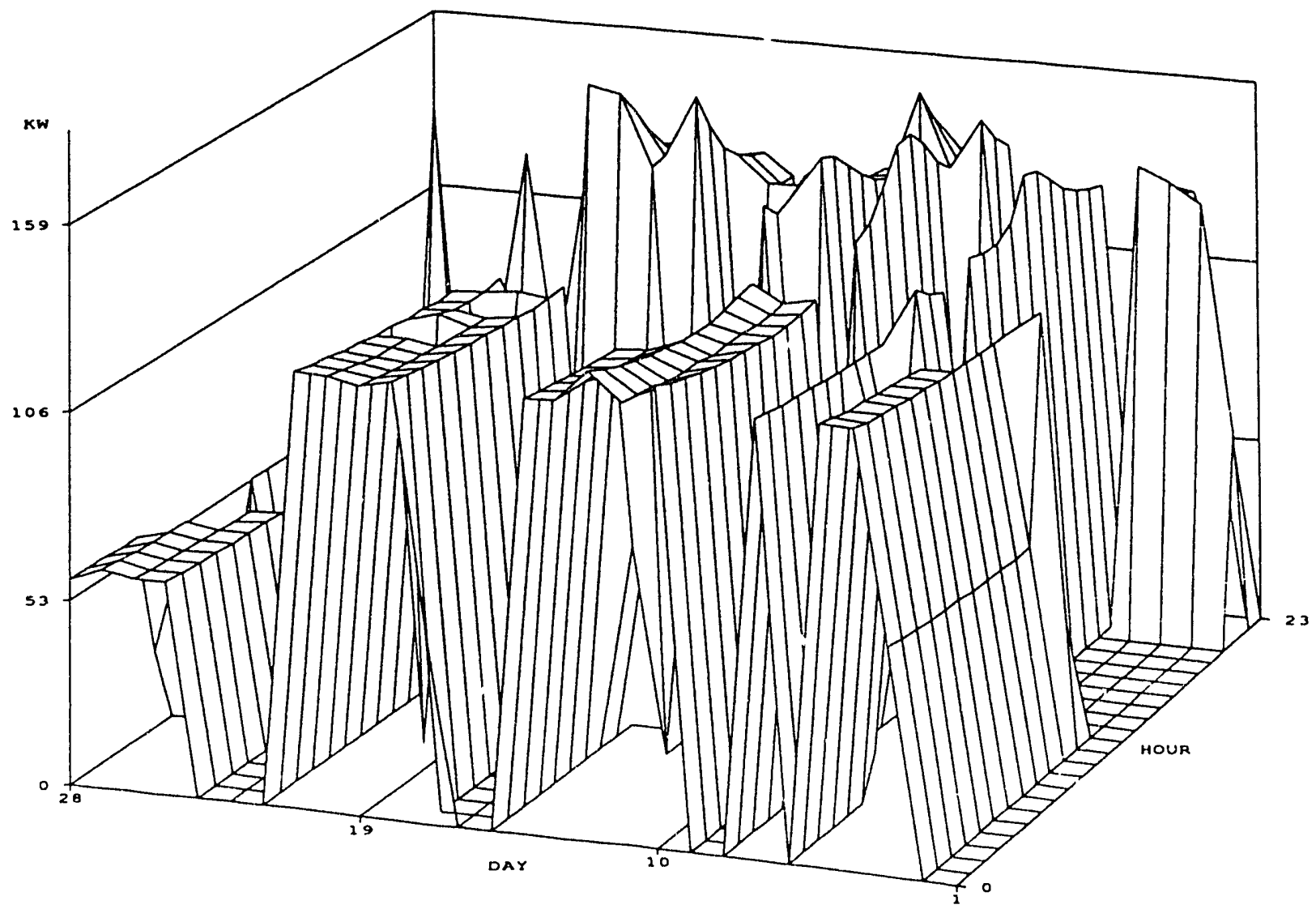


Figure 16. Case Study 2: June 1987 Cooling Load

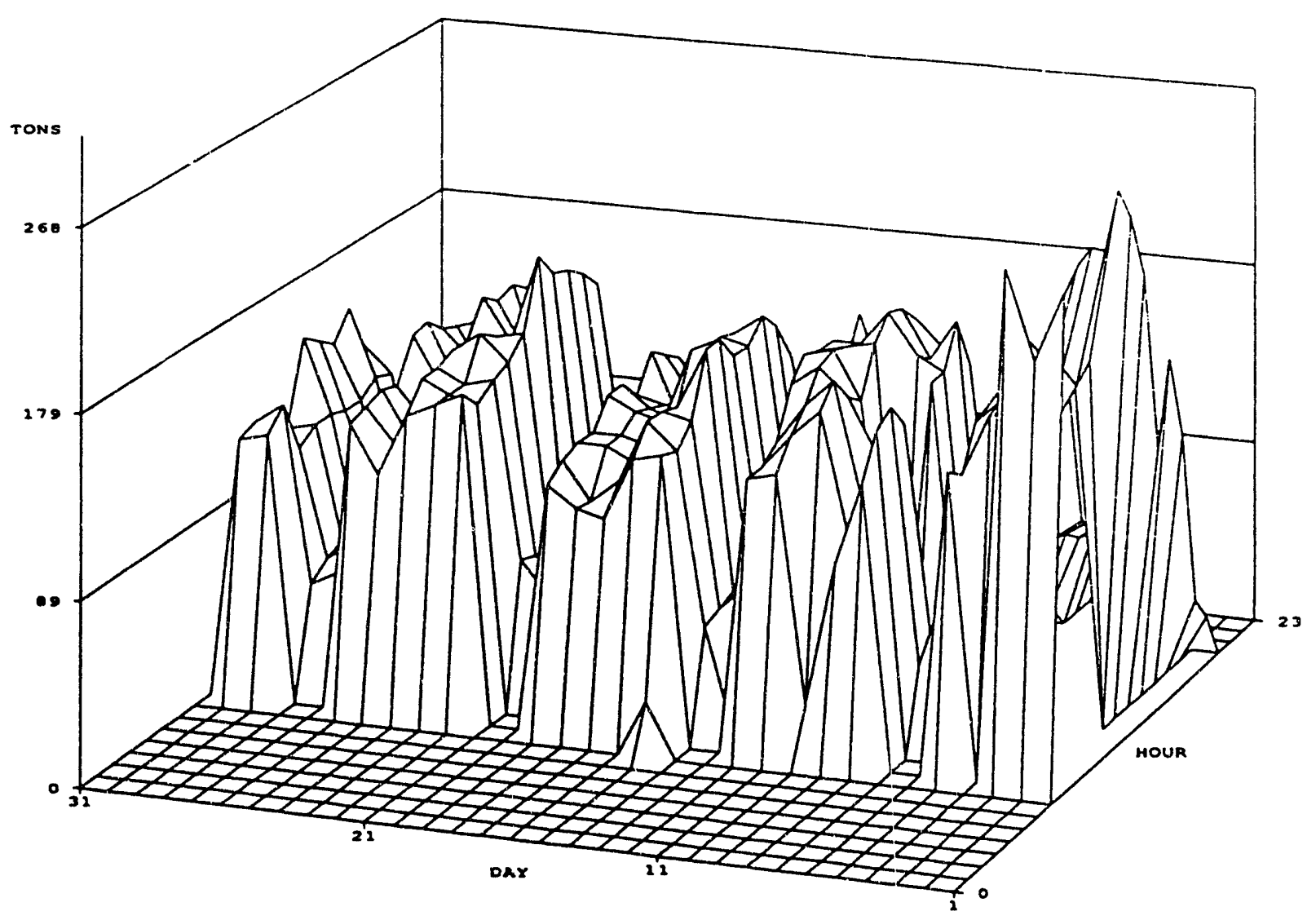

Figure 17. Case Study 2: Electricity Demand by TES Compressors in June 1987

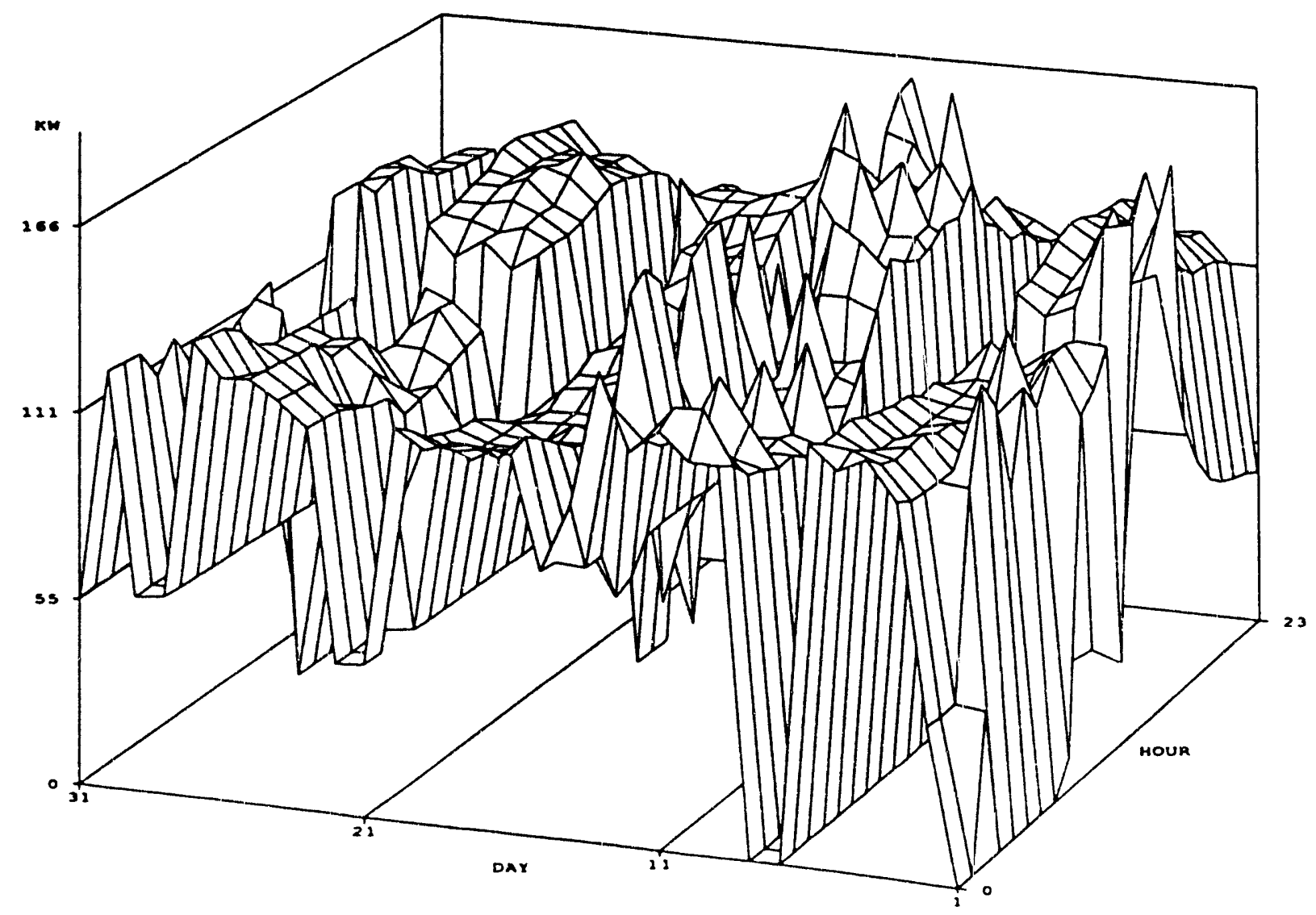


It can be seen from Table 9 that with roughly the same loads, the system required considerably more electricity for compressors and pumps in June. During on-peak hours, 4.4 MWh/week were used in June as opposed to $2.0 \mathrm{MWh} /$ week in February. During off-peak hours, the same TES system used 3.6 MWh more in one week in June than in February. This might be because of the encountered problems in the same period which we mentioned in the previous section. But obviously the system was not performing properly in June 1987.

Under these circumstances, it may be misleading to compare a TES system to a conventional system using the data for the summer months. Fortunately, because of the shape of the building and the climatic conditions in San Francisco, building loads are mostly internally driven and usually there is not a significant difference between summer and winter months. It is quite common to come across days that are typical of winter days during the foggy months of the summer. It should be noted from Table 9 that the COP for the TES system can be calculated to be 2.63 (9 kton-hours / $(2.3 \mathrm{MWh}+9.8 \mathrm{MWh})$ ) for the February week. This confirmed that at least during this period, the system was performing close to normal operation.

Table 10 compares the performance of the TES system with the three conventional system configurations. The TES saved peak power with insignificant energy penalties when compared with onechiller conventional system. However, when the TES performance was compared with split- and twochiller systems, the peak power savings became insignificant and ene:gy penalties become dominant. As in the Case 1, we continued our analysis assuming a two-chiller conventional system.

Table 10.

Savings in Electricity Use and Peak Demand Due to the Existing TES System

Compared to Simulated Conventional Chilled-Water Systems

for the Third Week of February 1987.

\begin{tabular}{|c|c|c|c|c|c|c|}
\hline & \multicolumn{4}{|c|}{ Electricity Use } & \multicolumn{2}{|c|}{ Building Peak } \\
\hline & $\begin{array}{c}\text { On-peak } \\
\text { 12:00-6:00, } \\
\text { Mon.- Fri. } \\
\text { MWh }\end{array}$ & $\begin{array}{c}\text { Part-peak } \\
\text { 8:30-12:00, } \\
\text { 18:00-21:30, } \\
\text { Mon.- Fri. } \\
\text { MWh }\end{array}$ & $\begin{array}{c}\text { Off-Peak } \\
\text { All other } \\
\text { times } \\
\text { MWh }\end{array}$ & $\begin{array}{l}\text { Total } \\
\text { MWh }\end{array}$ & $\begin{array}{c}\text { On-peak } \\
\text { kW }\end{array}$ & 24-hour \\
\hline $\begin{array}{l}\text { Measured Data } \\
\text { TES system } \\
\end{array}$ & 1.9 & 4.4 & 5.7 & 12.0 & 1130 & 1130 \\
\hline & \multicolumn{4}{|c|}{ Weekly Savings } & \multicolumn{2}{|c|}{ Peak Reduction } \\
\hline $\begin{array}{l}\text { Simulation } \\
\text { Single Chiller } \\
\text { Split Chiller } \\
\text { Two Chillers }\end{array}$ & $\begin{array}{l}4.7 \\
2.6 \\
2.8\end{array}$ & $\begin{array}{l}-0.2 \\
-0.9 \\
-0.6\end{array}$ & $\begin{array}{l}-5.3 \\
-5.4 \\
-5.3\end{array}$ & $\begin{array}{l}-0.8 \\
-3.7 \\
-3.1\end{array}$ & $\begin{array}{r}140 \\
10 \\
20\end{array}$ & $\begin{array}{r}140 \\
10 \\
20\end{array}$ \\
\hline
\end{tabular}

(1) One chiller twice the size of the other. 
Table 11 presents the savings in electricity use and demand reduction due to the use of TES system compared to a conventional system. The conventional system consists of two chillers where one has twice the capacity of the other. Table 12 shows the measured performance of the TES system for the winter and summer weeks.

Table 11.

Savings in Electricity Use and Peak Demand Due to the TES System Compared to a Conventional System Under Different Load Scenarios

\begin{tabular}{|c|c|c|c|c|c|c|}
\hline & \multicolumn{4}{|c|}{ Weekly Savings } & \multicolumn{2}{|c|}{ Peak Reduction } \\
\hline Load Type & $\begin{array}{c}\text { On-peak } \\
\text { 12:00-6:00, } \\
\text { Mon.- Fri. } \\
\text { MWh }\end{array}$ & $\begin{array}{c}\text { Part-peak } \\
\text { 8:30-12:00, } \\
\text { 18:00-21:30, } \\
\text { Mon.- Fri. } \\
\text { MWh }\end{array}$ & $\begin{array}{c}\text { Off-Peak } \\
\text { All other times }\end{array}$ & MWh & On-peak & 24-hour \\
\hline $\begin{array}{l}\text { Simulation } \\
\text { Feb. } 87 \text { 3rd week } \\
\text { June }^{(1)} \\
\text { 3rd week }\end{array}$ & $\begin{array}{r}2.8 \\
-0.6\end{array}$ & $\begin{array}{l}-0.6 \\
-1.5\end{array}$ & $\begin{array}{l}-5.3 \\
-7.2\end{array}$ & $\begin{array}{l}-3.1 \\
-9.3\end{array}$ & $\begin{array}{l}21 \\
-2\end{array}$ & $\begin{array}{l}21 \\
-2\end{array}$ \\
\hline
\end{tabular}

(1) A Typical Week in Winter

${ }^{(2)}$ A Typical Week in Summer

Table 12.

Electricity Use and Demand for the Existing TES System

\begin{tabular}{|c|c|c|c|c|c|c|c|c|}
\hline & \multicolumn{4}{|c|}{ Electricity Use } & \multicolumn{4}{|c|}{ 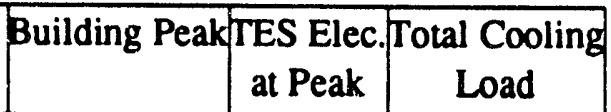 } \\
\hline Load Type & $\begin{array}{r}\text { 12:00-6:0 } \\
\text { Mon.- Fr } \\
\text { MWh }\end{array}$ & $\begin{array}{r}\text { On-pe } \\
\text { 8:30-12:( } \\
\text { 18:00-21: } \\
\text { Mon.- Fr } \\
\text { MWh }\end{array}$ & $\begin{array}{l}\text { All othe } \\
\text { times } \\
\text { MWh }\end{array}$ & & $\mathrm{kW}$ & t-peak & Off-Peak & 100 ton-hour \\
\hline $\begin{array}{l}\text { Measured Data } \\
\text { Feb. } 87 \text { 3rd week } \\
\text { June } 87 \text { 3rd week }\end{array}$ & $\begin{array}{l}1.9 \\
4.4\end{array}$ & $\begin{array}{l}4.4 \\
4.5\end{array}$ & $\begin{array}{l}5.7 \\
9.3\end{array}$ & $\begin{array}{l}12.0 \\
18.2\end{array}$ & $\begin{array}{l}1130 \\
1110\end{array}$ & $\begin{array}{l}1130 \\
1110\end{array}$ & $\begin{array}{l}159 \\
159\end{array}$ & $\begin{array}{l}9.0 \\
9.1\end{array}$ \\
\hline
\end{tabular}

(1) A Typical Week in Winter

(2) A Typical Week in Summer

As mentioned before, the performance of the TES system deteriorated during the summer season and there were no data that would indicate the system performance under normal conditions. Therefore, we attempted to use the winter data for performance evaluation. The performance of the system in a typical week in winter as shown in Table 11 can be viewed to be an upper limit for the performance on a typical day for this building and climate in summer. This is because of the fact that in summer with higher 
outdoor temperatures and lower overall COP of chillers, the energy required for cooling may increase even though the load may be similar.

Considering only the winter data, it can be seen from Tables 11 and 12 that the TES system shifts $60 \%$ $(2.8 /(2.8+1.9))$ of the on-peak electricity use to other periods, which exactly corresponds to the design intent. The data showed a peak reduction of only $12 \%(21 /(21+159))$. Although there was considerable electricity use shift, this was accompanied by twice as much energy use increase during the off-peak hours. This was mostly because of the lower efficiency of the TES system due to the heat exchanger inefficiencies and other losses. It is obvious that there would not be much dollar savings.

\section{Summary}

The performance of the TES has not been as high as the predicted level at the design stage. Most of the problems in this building stemmed from the fact that all of the equipment including the TES was sized with only enough capacity to meet the loads on the design peak day. This way the TES system was justified on a first cost basis and any savings from the peak reduction and electricity load shift considered as a bonus. Unfortunately, the system as built was not able to produce chilled water at the low temperatures assumed at the design stage. This created a whole series of problems including having to run the compressors during peak hours and also having to make radical changes in the air distribution system. The increases in the internal load levels made the situation even worse.

The problems encountered throughout the life of the building are:

\section{Design Related}

Storage, evaporators, and the air distribution system were sized at a minimum level. Increases in cooling load due to changing intemal loads were not contemplated in the design stage. The TES system was designed to be operated manually; therefore it is impossible to implement any decent control strategy. Minor problems stemming from the layout were related to the cooling towers. No extra capacity was added to the system to facilitate extended maintenance and repairs. There were no provisions for future expansion.

\section{Installation Related}

The equipment was not cleared of construction debris. We do not have any information on whether proper acceptance testing was performed.

\section{Operation Related}

The expansion valve controls created problems. To increase capacity, at one point in time, superheat controls were disconnected to improve heat transfer properties of the evaporator, but this led to pressure fluctuations in the refrigerant compressors resulting in compressor failures. The superheat controls had to be reactivated again. This was a problem basically stemming from shortage in capacity.

Bridging ice fields and overcharging ice storage also posed as problems. Overcharging was caused by non-functioning ice thickness controls. Ice fields formed due to uneven distribution of the refrigerant to the different tanks. These two different problems degraded the melting performance of the stored ice and chilled water temperature was produced at a higher temperature than the designed $38^{\circ} \mathrm{F}$. On a peak day, 
the load could not be met and on average days more ice than required had to be build to compensate for the inefficient melting process.

There were almost no sensors except for those installed by PG\&E for their monitoring project. Under the circumstances, PG\&E data were used to evaluate the TES performance. There were no means of implementing any computerized control strategy because the building is under pneumatic control.

\section{Maintenance Related}

The problems related to maintenance included:

- there were no established performance monitoring procedures,

- it was hard to access certain equipment when repairs were required, and

- tube fouling occurred because water was not filtered. 


\section{Chapter 4}

\section{Analysis of TES Performance}

In this chapter, we provide an overview of the analysis of the case studies and summarize the historical performance of the TES systems. We also review the results presented in the detailed case studies and compare the monitored TES experience with the design intention. This chapter concludes the report by recommending a few research project for further consideration.

\section{Design, Installation, Operational, and Maintenance Issues}

Tables 13 and 14 present a summary of design and operational issues related to the two case studies. Table 15 further details and integrates the problems identified in the case studies. In a similar table, Piette et al. [8] have summarize problems with TES systems for 10 buildings.

The identified problems are grouped into issues related to design, installation, operation, and maintenance of the systems. In reviewing the information in Tables 13 through 15 , two immediate observation can be made: (1) almost all problems related to the operation of TES and non-TES systems can be traced back to the design of the system, and (2) the identified problems are not unique to TES systems. There are as many original problems with the "conventional" HVAC systems as with TES systems. In a way both thiese factors are inter-related. The traditional design of HVAC systems include many safety factors and rule-of-thumb figures summarizing many years of in-field engineering experience. Although there is insufficient literature on the actual operation and performance of conventional systems, judging from the problems related to non-TES components identified in these two case studies, it is possible to believe that many conventional systems have problems of their owns, but a failure in a TES system may have a more dramatic impact on thermal comfort and electricity charges. Under- or over-sizing of the equipment, faulty or malfunctioning equipment, poor design and installation, installation of sub-standard equipment, etc. are not unique to TES systems.

The objective of the designers of the TES systems in case study buildings were to design just-the-rightsize systems so that both the initial investment and operating costs were minimized. This is evident since systems had to be expanded after commissioning. Under such conditions, a system is usually designed only for normal and steady-state operating conditions which usually precludes due consideration to factors such as maintenance issues, growth in the needed capacity, ease of the operation, and modularity of the systems. But, once the system is installed, the building occupants and operators rightfully expect quality performance of the system under all conditions and at all times. Designing for $100 \%$ reliability simply costs more. Moreover, both these costs and consequences of failure are much greater for TES than a conventional system.

Therefore, it is not surprising to note that these systems, at least initially, have not performed to the design intent and expectation and they have gone through extended periods of trouble-shooting. Also, it is worth noting that in these buildings (and perhaps many other commercial buildings) the design guidelines themselves are moving targets-building loads grow, owners change, equipment is replaced, etc. 
Table 13.

Design and Operational Issues for Case Study 1.

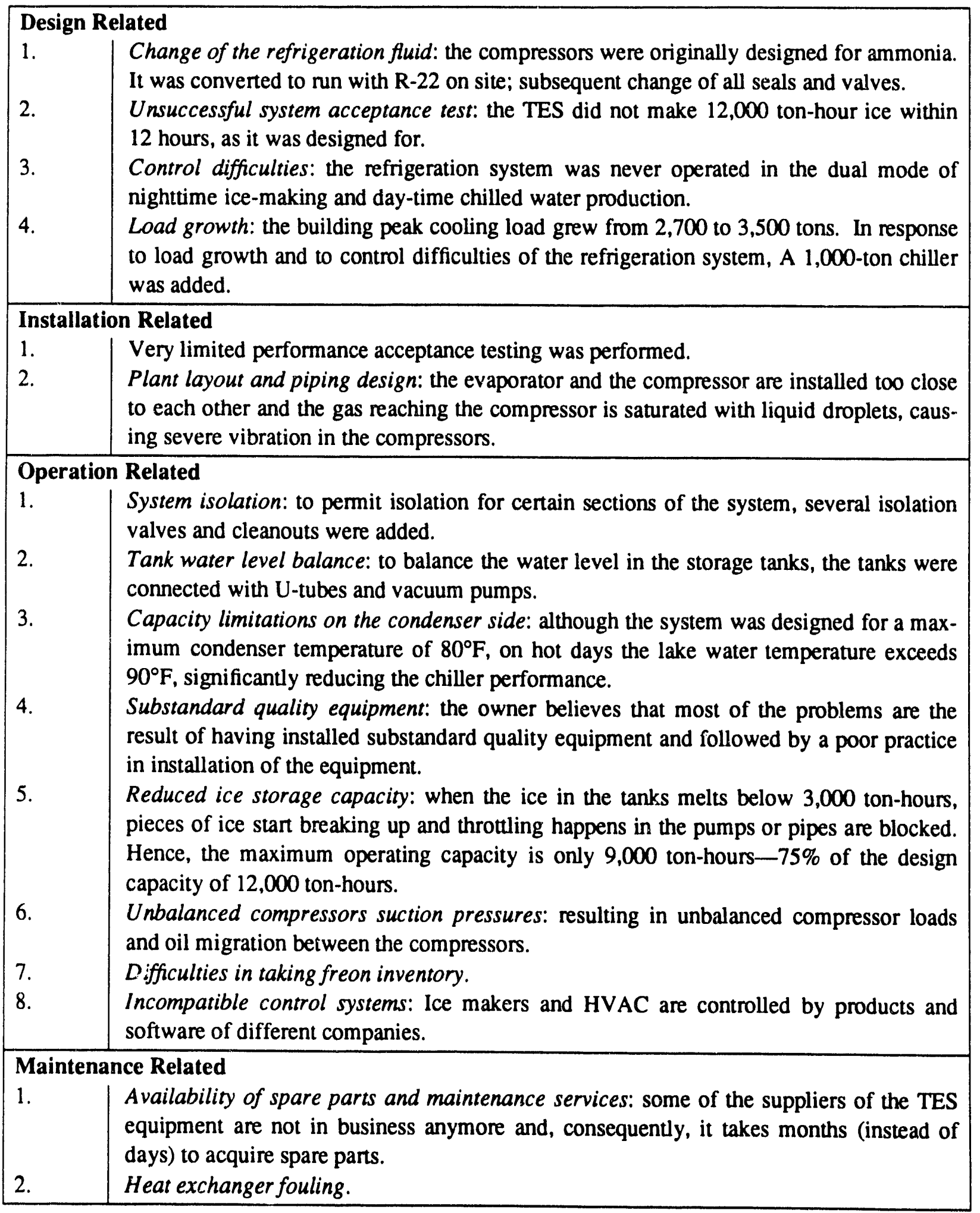


Table 14.

Design and Operational Issues for Case Study 2.

\begin{tabular}{|c|c|}
\hline \multicolumn{2}{|r|}{ Design Related } \\
\hline 1. & $\begin{array}{l}\text { Equipment sizing: storage, evaporators and air distribution system were sized at a } \\
\text { minimum level. Load increases were not contemplated at the design stage. } \\
\text { Control: the TES was designed to be run manually therefore it is difficult to implement } \\
\text { any automated control strategy. } \\
\text { Maintenance provisions: No extra capacity was added to the system to facilitate extended } \\
\text { maintenance and repairs. }\end{array}$ \\
\hline \multicolumn{2}{|r|}{ Installation Related } \\
\hline 1. & $\begin{array}{l}\text { Acceptance test: we do not know of any proper acceptance testing. Reports indicate that } \\
\text { the equipment was not cleared of construction debris. }\end{array}$ \\
\hline \multicolumn{2}{|r|}{ Operational Related: } \\
\hline 1. & $\begin{array}{l}\text { Expansion valves: repeated problems with both manual and thermostatically controlled } \\
\text { expansion valves. }\end{array}$ \\
\hline 2. & $\begin{array}{l}\text { Bridging of ice field: repeated occurrence of bridging of ice fields leading to capacity } \\
\text { shortage. }\end{array}$ \\
\hline 3. & Non-functioning start stop time clock: leading to ice storage overcharging. \\
\hline 4. & $\begin{array}{l}\text { Control: the absence of sensors and controls make operation difficult. Ice thickness con- } \\
\text { trols had been disconnected. }\end{array}$ \\
\hline 5. & Compressor failure: due to wildly fluctuating head pressures \\
\hline \multicolumn{2}{|c|}{ Maintenance Related } \\
\hline 1. & $\begin{array}{l}\text { Equipment layout: hard to access certain equipment when repairs are required. Also, it } \\
\text { was discovered that due to the location of the cooling tower in a recessed well covered by } \\
\text { catwalks, the back-draft was creating a short-cycling of the cooling tower fans thereby } \\
\text { compromising the heat rejection. } \\
\text { Tube fouling: because of non-filtered water }\end{array}$ \\
\hline 2. & Tube fouling: because of non-filtered water \\
\hline
\end{tabular}


Table 15.

Identified Problem Areas for the Two Case Studies.

The consequences of the problems indicated are more severe in some cases than the others.

\begin{tabular}{|c|c|c|}
\hline & Case 1 & Case 2 \\
\hline $\begin{array}{l}\text { DESIGN } \\
\text { Storage Sizing } \\
\text { Distribution System Sizing }^{(1)} \\
\text { Condenser Sizing }{ }^{(1)} \\
\text { Evaporator Sizing }^{(1)} \\
\text { Environmental Changes }^{(1)} \\
\text { Changes in Load Levels } \\
\text { Rules and Regulations }^{(1)} \\
\text { Isolation of Sections for Maintenance }^{(1)} \\
\text { Refrigerant Storage for Maintenance } \\
\text { Extra Capacity for Maintenance }^{(1)} \\
\text { Improper Layout }^{(1)} \\
\text { Oil Recovery }^{(1)} \\
\text { Provisions for Future Expansion }^{(1)}\end{array}$ & $\begin{array}{l}X \\
X \\
X \\
X \\
X \\
X\end{array}$ & $\begin{array}{l}X \\
X \\
X\end{array}$ \\
\hline $\begin{array}{l}\text { INSTALLATION } \\
\text { Cleaning After Construction } \\
{ }^{(1)} \\
\text { Proper Acceptance Testing } \\
\end{array}$ & $X$ & $\begin{array}{c}X \\
(2)\end{array}$ \\
\hline $\begin{array}{l}\text { OPERATION } \\
\text { Control System } \\
\text { Expansion Valve Setting } \\
\text { Time Clock } \\
\text { Use of All of the Ice Capacity } \\
\text { Compressor Failures } \\
\text { Refrigerant Leaks }^{(1)} \\
\text { Ice Thickness Control } \\
\text { Overcharging } \\
\text { Bridging of Ice Fields } \\
\text { Maintaining Chilled Water Design Temperature } \\
\text { Oil Contamination } \\
\text { Balancing Fluid level in Tanks } \\
\text { Comfort Level During a Peak Day } \\
(1)\end{array}$ & $\begin{array}{l}X \\
X \\
X\end{array}$ & $\begin{array}{l}X \\
X \\
X \\
X \\
X \\
X \\
X \\
X \\
X \\
X \\
X\end{array}$ \\
\hline $\begin{array}{l}\text { MAINTENANCE } \\
\text { Performance Monitoring+Sensor Calibration } \\
\text { Water Filtration } \\
\text { (1) } \\
\text { Service and Spare Parts } \\
\text { Substandard Quality of Material and Equipment } \\
\text { Accessibility of Equipment }^{(1)}\end{array}$ & $\begin{array}{l}X \\
X \\
X\end{array}$ & $\begin{array}{l}X \\
X\end{array}$ \\
\hline
\end{tabular}

(1) These problems are not unique to TES systems; they can occur in conventional systems as well.

(2) Data not available. 
Neither of the two cases had gone through a successful performance acceptance test and the systems had to go through a significant period of trouble-shooting and modifications before they becarne fully operational (actually shift peak power). The industry can benefit substantiaily from the introduction of a standard protocol for performance testing of systems. A successful protocol needs to address problems and define "performance" as well as provide guidelines for completion of a successful performance test and to suggest remedies for overcoming possible problems. Problems such as cleanup of the system from construction debris, vibration of the compressors, and control of the system can usually be identified during the performance test of the system.

As we discussed in Chapters 2 and 3, the measured performance of the case study TES systems has not been totally disappointing. In the first case, after an initial period of trouble-shooting and significant changes in operational strategies, the TES performed close to its modified design intent. Some of the design guidelines had been modified to address operational issues such as ease of control and maintenance of the system. In the second case, the system was in fact under-sized and its capacity had not been sufficient to respond to growing cooling loads of the building.

Control of TES systems in these two buildings appeared to be a major source of some of the identified problems. In one case, the system had hardly any control; in the other case, the control hardware and software-purchased from a variety of vendors-were to a certain extent incompatible. Without proper control, it is very difficult to maintain a sustainable operation, let alone the optimal operation of the system. Ease of the operation should be one of the principle factors in designing control systems.

Still, there are some problems with TES that are unique to the system and which are poorly understood. Ice bridging is one such problem. Fortunately, the industry has researched this problem and offered solutions.

\section{Measured performance}

An integral objective of this study was to compare the energy performance of the case study TES systems with those of the conventional airconditioning systems. The available data from PG\&E included hourly building thermal loads and consumption of the various TES components. In analyzing the available data, a week was taken as the minimum unit of time since the ice built in one day can be used several days later. Several weeks with complete data were selected. Weeks with similar load profiles were compared to highlight problems with the system performance under different operating strategies.

A key parameter in estimating the performance of a conventional chiller is the coefficient of performance (COP). Chiller performance depends on numerous factors such as its cooling load, condenser temperature (a function of outside weather conditions), and its control strategies. We tried to estimate the COPs of the chillers from the measured data. In their analysis, PG\&E has used an average COP of 2.71. In a previous study for one of the cases, the researcher assumed a maximum COP of 5 for the compressor and estimated the average COP for the system in the range of 2.74 to 2.86 for the period studied [5]. In our study, we employed a single and two multi-chiller configuration and used a quadratic relation to estimate the part-load efficiency of the system. Using the measured data, we calculated the maximum COP for the conventional chillers to be 6 . 
Table 16 presents a suminary of our comparisons for both case studies. For these comparisons, we selected a summer week for the first case and a winter week for the second case.

For Case 1, the TES system has saved 640,780 , and 660 on-peak kW for single chiller, split chiller, and two-chiller systems, respectively, at a cost of additional energy use of 20.5, 37.6, 47.2 MWh per week. For Case 2, the diumal energy performance of the conventional single-chiller system and the TES system were comparable; however, the TES system used less power than the conventional system. Once the performance of the TES with split and two-chiller conventional systems were compared, the energy penalties increased substantially and the peak power savings diminished. Obvicusly, in both cases TESs have saved power and energy during the peak period. But the total weekly energy use of TES systems was much higher than the conventional systems. Two main reasons for the higher energy use of TES systems are: (1) lower COP of the chillers when they were making ice (about $40 \%$ lower) and (2) the inefficiencies of iced-water/chilled water loop heat exchangers in the TES systems.

Table 16.

Savings in Electricity Use and Peak Demand Due to the Existing TES System Compared to Conventional Chilled-Water Systems.

\begin{tabular}{|c|c|c|c|c|c|c|c|}
\hline \multirow{3}{*}{ Configuration } & \multicolumn{5}{|c|}{ Weekly Savings with TES } & \multirow{2}{*}{\multicolumn{2}{|c|}{$\begin{array}{c}\text { Peak Cooling } \\
\text { Reduction }\end{array}$}} \\
\hline & \multirow{2}{*}{$\begin{array}{c}\text { On-peak } \\
\text { MWh }\end{array}$} & \multirow{2}{*}{$\begin{array}{c}\text { Part-peak } \\
\text { MWh }\end{array}$} & \multirow{2}{*}{$\begin{array}{c}\text { Off-peak } \\
\text { MWh }\end{array}$} & \multicolumn{2}{|c|}{ Total } & & \\
\hline & & & & MWh & $\%$ & kW & $\%$ \\
\hline \multicolumn{8}{|c|}{ Case 1: a summer week (3rd week of August 1990) } \\
\hline Single Chiller & 15.0 & 0.3 & -35.8 & -20.5 & -20 & 640 & 54 \\
\hline Split Chiller & 16.9 & -3.5 & -51.0 & -37.6 & -43 & 780 & 59 \\
\hline Two Chillers ${ }^{(1)}$ & 13.5 & -4.9 & -55.8 & -47.2 & -63 & 660 & 54 \\
\hline \multicolumn{8}{|c|}{ Case 2: a winter week (3rd week of February 1987) } \\
\hline Single Chiller & 4.7 & -0.2 & -5.3 & -0.8 & -7 & 140 & 47 \\
\hline Split Chiller & 2.6 & -0.9 & -5.4 & -3.7 & -45 & 10 & 6 \\
\hline Two Chillers ${ }^{(1)}$ & 2.8 & -0.6 & -5.3 & -3.1 & -35 & 20 & 11 \\
\hline
\end{tabular}

(1) One chiller twice the size of the other.

It is also important to note that the energy performance of split chiller systems is much superior to that of the single-chiller system. However, the operation of the split-chiller systems needs more sophisticater control than the single-chiller system. Similarly, an optimal design and control for the TES system can yield substantially better energy performance than the existing TES installations.

In Chapters 2 and 3, we discussed the performance of the case study TES systems in further detail and estimated savings in monthly electricity bills for each case. The case studies could have been more complete if we could have performed a cost-benefit analysis for the TES systems. But, unfortunately, we were not able to obtain cost data for these TES installations. 


\section{Conclusions}

The TES case studies developed and analyzed in this project are limited to the application of partial ice storage in office buildings in the San Francisco Bay Area. For both cases, there are significant differences between the design intentions and the installed systems. In addition, both systems have gone through major trouble-shooting periods. The initial complications have included problems related to both TES and non-TES components and equipment. Based on the analysis of the case-study buildings (see Table 15), it is logical to assume that components of conventional systems have as many initial problems as TES systems. Both conventional and TES systems could benefit from a detailed commissioning and performance accepting tests where the initial trouble shooting can be a component of design and installation.

It should be noted that in our analysis we compared measured TES performance data to simulated conventional system performance. In these comparisons, we did not account for the inefficient utilization of the TES systems. Optimizing the strategies for both TES and conventional systems was beyond the scope of this project. Such an effort should be considered in future projects. The simulation tools developed for the above comparisons can be modified and expanded for such a function.

In this project, the primary objective was to perform case studies rather than modeling; hence, we simplified the simulation of the condenser by ignoring the effect of outdoor temperature variations. Our simplified calculations showed that increases in outdoor temperatures may increase the chiller electricity demand up to $20 \%$ depending on the type of compressor and refrigerant fluid. Such an increase in compressor electricity consumption can be controlled by more intensive use of the condenser-side equipment like the cooling towers, if it happens to be a less expensive option.

\section{Recommendations}

Some of the issues that were discussed in this report need further investigation. To respond to some of the problems discovered in these case studies and address some of the current research needs of TES systems, we propose the following research ideas to CIEE for further consideration.

\section{Cost-Benefit Analysis of TES Systems: Customer and Utility Perspectives}

TESs are installed to save peak power. It is of interest to customers to avoid costly peak power charges by running their cooling equipment during off-peak hours; and it is of interest to the electric utilities to avoid operating the expensive generation units during the peak hours and shift the load to off-peak periods. Shifting the load to off-peak periods improves the utility system load factor and hence saves peak power requirements. Consequently, the utilities provide incentives to enhance the penetration of this technology. But in reality, many systems do not operate as designed and hence do not shift loads as was originally intended. Ultimately, the customer does not get his money's worth by not being able to reduce his demand costs as planned and the utility does not see the peak load reduction it paid for. The literature indicates that the most beneficial application of TES is when the customer provides the cooling needs required by building or activity expansion by installing storage and using the existing chillers during the night to charge the storage (rather than installing new chillers to provide active cooling during the day) [14]. Also the application of TES for security back-up of environmentally sensitive zones, such as clean room and computer room operations, are examples of successful TES installations [15]. Under these conditions, utilities also benefit by providing less incentives for a higher payback. 
We recommend a study to analyze the available data and perform a cost-benefit analysis of TES systems both from utilities and customer perspectives. The project should collect cost data on system installation, cost data on utility incentives, measured performance data of TESs, and develop indicators for future reference. Furthermore, we suggest extending the research to investigate the design of utility incentive programs that would provide maximum $b$ iefits to both customers and utilities [8].

\section{Procedures and Algorithms for Optimal Control of TES systems}

Most TES systems are controlled simply by fully charging the system during off-peak hours and using only the stored capacity to the extent needed during the operating hours of the building (provided that they do not run out of capacity). Few of these systems have the required control software to take advantage of the daily climatic and operational variations by optimizing the system charging and discharging strategies. Consequently, even in systems that operate as planned, the lack of an "adaptive" control system results in inefficient use of the resources and hence higher energy costs.

We recommend a collaborative effort with control manufacturers to review the current state-of-the-art control technologies applicable to TES systems. This should include a review of control hardware, control strategies, and software for implementing the control strategies. Such an adaptive control system may reside in a stand-alone control loop for the TES or can be integrated with the existing Energy Management and Control System (EMCS) of a building. A case study of an adaptive control system will provide feedback on the actual operation of the system and the operator's acceptance of such an advanced control system.

\section{Designing TES for F'lexibility}

Presently, TES systems are designed for the so-called "design-day" conditions. But in reality, the systems are rarely operated under the design-day conditions. Furthermore, in the process of designing TES, the changing utility rates and future operational changes in the building-both in terms of change in the operating conditions and expansion of activities - are not considered. As a result, TESs are designed to operate in a non-optimal fashion.

We recommend a research project to review the current desigi practices for TES and variations in conventional design in view of the need for flexibility. Flexibility is needed to handle changes in thermal variables, such as increased cooling loads, and other factors related to specific California conditions, such as electricity rate and expansion of the customer facility. In this project, those systems and system designs that most easily accommodate change should be identified.

\section{Methods to Improve the Dynamic Operations of TES Systems}

An excellent environment in which to discuss TES and receive valuable feedback is the conventions held by ASHRAE; a substantial number of TES manufacturers, operators, and building professionals attend the ASHRAE conferences. We organized a forum for the ASHRAE summer 1991 meeting. This forum discussed possible operational and design problems of TES, and reviewed remedies and operator/contractor responses to problems. The information provided in that forum can be used to design a project to identify methods for improving the dynamic operations of TES systems. 


\section{Energy Management Control Systems for Performance Monitoring of TES}

Large and complicated TESs can benefit from continuous monitoring systems; however, currently installed TES systems are not equipped with such monitoring systems. On the other hand, an increasing portion of :lew and retrofitted large commercial buildings are equipped with EMCSs. An integrated EMCS/TES system can provide an ideal environment for performance monitoring, preventive maintenance, and trouble-shooting of TES systems. Furthermore, EMCSs can house advanced control software for optimal operation of TESs. In addition, they provide an interface to the utility to communicate and assist the building operator in the operation of the system.

We recommend a project to study the potential of an integrated EMCS/TES systems in terms of better operation and trouble-shooting of TES. A list of suggested tasks for this project include: a review of current TES control strategies performed through EMCSs, an analysis of trends in control design and application of TES, development of a case study for analysis of a various TES related options, and possibly developing software for on-line performance testing and trouble-shooting of TES.

\section{Application of Knowledge-based Systems to TES System, Operation, Maintenance, and Trouble- Shooting}

A majority of the problems with TES stem from improper design, improper installation, and finally lack of operational experience with the system. A Southem California Edison study reports that the problems of many TESs in their service area have been remedied by visits of an expert group to the sites and the performance of short-term diagnostic measurements.

We recommend a project to develop a demonstration knowled;ze-based system to aid operators and contractors to trouble-shoot TES systems and help alleviate problems. The demonstration knowledge-based system (KBS) should examine possible operational and design problems of TESs and suggest remedies and operator/contractor responses to problems. This KBS may focus on a variety of TES system types (water, ice, and phase change) with a variety of operational strategies (full storage, partial storage, and demand limiting). The KBS should also address the application of TES to industrial process loads (nonHVAC) such as refrigerator, freezer, and cold storage.

\section{New-Generation TES Systems}

In view of the operating problems with the first-generation and on-site built TES systems, the manufacturers are moving towards the design of a new-generation TES system. These new-generation des:gns are moving in the direction of modularity and packaged systems, which are intended to preclude many operational problems of TES. In addition, the operator interaction with the new systems are simultaneously enhanced and simplified. Although the new generation TESs will probably resolve many of the existing problems, they may potentially introduce new complications and problems.

We recommend a collaborative effort between CIEE and manufacturers of advanced TES systems to document the concept behind the design and implementation of these new systems. In the pmcess, CIEE will also have an opportunity to provide feedback on the TES problems and start-up verifications issues that are being collecting in this phase of the CIEE project. Additionally, we recommend development of a case study of a facility with a new-generation TES system. 


\section{References}

1. Electric Power Research Institute, "Opportunities in Thermal Storage R\&D," EPRI Report EM3159-SR, 1983.

2. Electric Power Research Institute, "Commercial Cool Storage Design Guide," EPRI Report EM3981, 1985.

3. Electric Power Research Institute, "Commercial Cool Storage Presentation Material," EPRI Report EM-4405, 1986.

4. Electric Power Research Institute, "Cool Storage Marketing Guidebook," EPRI Report EM-5841, 1988.

5. M. A. Piette, "Analysis of a commercial ice-storage system: Design principles and measured performance," Energy and Buildings, Vol. 14, pp. 337-350, 1990.

6. Electric Power Research Institute, "Performance of Cool Storage Systems," EPRI Report EM-4044, 1985.

7. Electric Power Research Institute, "Operation and Performance of Commercial Cool Storage Systems," EPRI Report CU-6561, 1989.

8. M. A. Piette, E. Wyan and J. Harris, "Technology Assessment: Thermal Cool Storage in Commercia! Buildings," Lawrence Berkeley Laboratory Repont LBL-25521, 1988.

9. M. A. Pietue, and J. Harris, "Program Experience Report: Commercial Cool Storage," Lawrence Berkeley Laboratory Report LBL-25782, 1988.

10. M. A. Piette, "Leaming from Experiences with Thermal Storage: Managing Electrical Loads in Buildings," CADDET Analysis Series Number 4, 1990.

11. T. A. Gilbertson and R.S. Jandu, "24-story office tower air-conditioning system employing ice storage--A case history," ASHRAE Trans., 89(2), 1984.

12. C. H. Jordan and M. Goto, "An Environmental System: Pacific Bell Complex," ASHRAE Journal, December 1985.

13. G. E. Schiller et al., "A field study of thermal environments and comfort in office buildings," ASHRAE Research Project 462, CEDR-04-088, American Society of Heating, Ventilation and Air-Conditioning Engineers, Atlanta, GA, 1988.

14. R. T. Tamblyn, "Chilled water storage goes to college," ASHRAE Journal, July 1987.

15. V. Racavelli, "Ice cooling cuts downtime, saves \$500,000," Energy User's News Magazine, June 1987. 

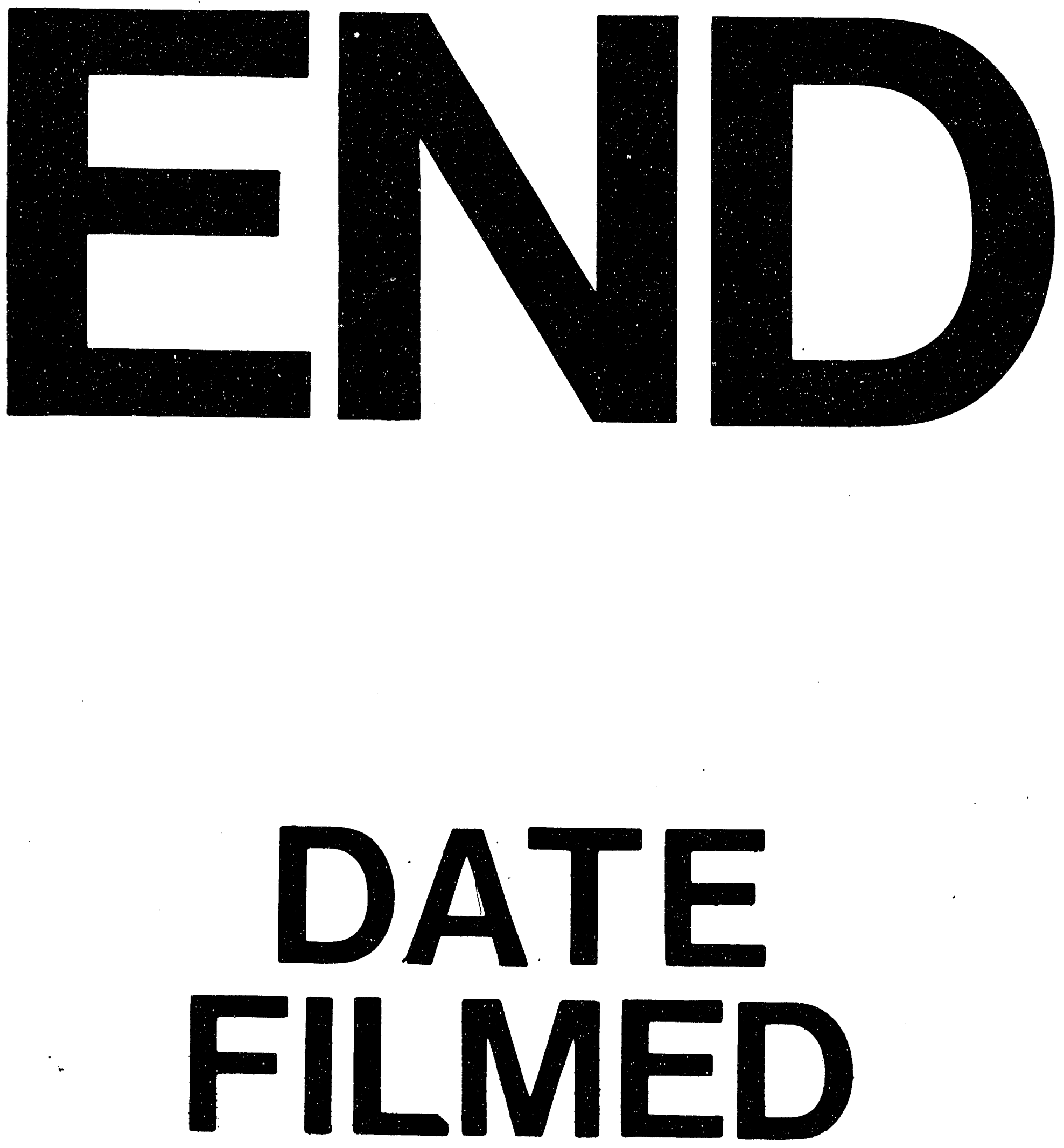

II
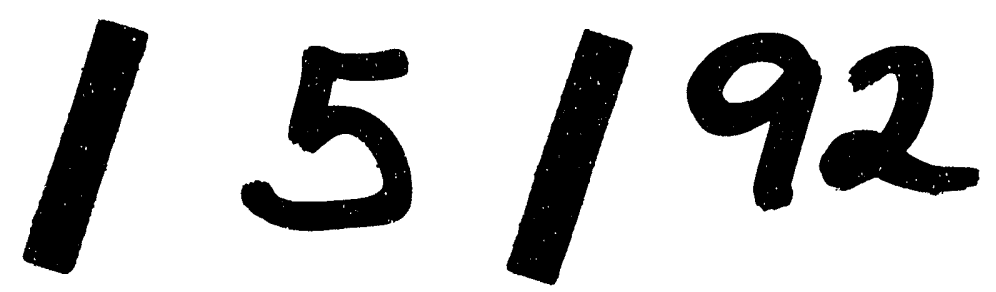

1 
